\title{
Surface Complexation Models: An Evaluation of Model Parameter Estimation Using FITEQL and Oxide Mineral Titration Data
}

\author{
KIM F. HAYES, ${ }^{* 11}$ GEORGE REDDEN ${ }^{\dagger}$ WENDELL ELA, ${ }^{\dagger}$ AND \\ JAMES O. LECKIE ${ }^{\dagger}$ \\ *Environmental and Water Resources Engineering, Department of Civil Engineering, University of Michigan, \\ Ann Arbor, Michigan 48109-2125 and ${ }^{\dagger}$ Environmental Engineering and Science, Department of \\ Civil Engineering, Stanford University, Stanford, California 94305
}

Received May 12, 1989; accepted November 16, 1990

\begin{abstract}
The ability of surface complexation models (SCMs) to fit sets of titration data as a function of changes in model parameters was evaluated using FITEQL and acid-base titration data of $\alpha$-FeOOH, $\alpha-\mathrm{Al}_{2} \mathrm{O}_{3}$, and $\mathrm{TiO}_{2}$. Three SCMs were evaluated: the triple-layer model (TLM), the constant capacitance model (CCM), and the diffuse-layer model (DLM). For all models evaluated, increasing the model input value for the total number of surface sites caused a decrease in the best-fit $\log K$ values of the surface protolysis constants. In the case of the $\mathrm{CCM}$, the best-fit surface protolysis constants were relatively insensitive to changes in the value of the capacitance fitting parameter, $C_{1}$, particularly for values of $C_{1}$ greater than $1.2 \mathrm{~F} / \mathrm{m}^{2}$. Similarly, the best-fit values of TLM surface electrolyte binding constants were less influenced by changes in the value of $C_{1}$ when $C_{1}$ was greater than $1.2 \mathrm{~F} / \mathrm{m}^{2}$. For a given $C_{1}$ value, the best-fit TLM values of the electrolyte binding constants were sensitive to changes in $\Delta \mathrm{p} K_{\mathrm{a}}$ up to $\Delta \mathrm{p} K_{\mathrm{a}}$ values of 3 . For $\Delta \mathrm{p} K_{\mathrm{a}}$ values above 3, no changes in the best-fit electrolyte binding constants were observed. Effects of the quality and extent of titration data on the best-fit values for surface constants are discussed for each model. A method is suggested for choosing a unique set of parameter values for each of the models.

(C) 1991 Academic Press, Inc.
\end{abstract}

\section{INTRODUCTION}

Surface complexation models (SCMs) are capable of simulating the experimentally observed acid-base titration properties of metal oxide minerals (1). They are also capable of simulating the adsorption of aqueous solution species as a function of $\mathrm{pH}$, solute concentrations, and ionic strength (2-4). For modeling sorption processes, SCMs offer a distinct advantage over the often used conditional distribution coefficient, $K_{\mathrm{d}}$, since SCMs represent surface chemical reactions with a set of quasi thermodynamic constants which are independent of changes in solution conditions (4). Since conditional constants are only applicable to the specific experimental conditions from which they have been estimated, they will not likely be able to account for spatial or temporal

${ }^{1}$ To whom all correspondence should be addressed. changes in solution composition that may occur in natural systems. Experimental evidence now exists showing that SCMs are capable of empirically modeling the chemical properties of complex mixtures of solids (5), and that they have the potential of becoming useful tools, in conjunction with groundwater transport models, for describing trace metal partitioning between the aqueous phase and mineral surfaces in aquifers (6).

In order for SCMs to be used to model sorption processes, parameters which adequately account for the acid-base protolysis reactions of the surface must be determined. This is typically accomplished by estimating the total surface site concentration for the solid of interest from surface area and hydroxyl site density measurements and performing acidbase titrations. Various methods have been suggested for parameter estimation from these 
type of data. However, depending on the method chosen, different values of model parameters for a given SCM and titration data may be obtained.

This paper describes a methodology for determining a unique set of model parameters from titration data for three commonly used SCMs, the diffuse-layer, constant-capacitance, and triple-layer models, based on their ability to simulate the acid / base titration behavior of oxide surfaces. These three models are similar in their descriptions of surface reactions, each treating the surface as if it were composed of amphoteric hydroxide functional groups which are capable of reacting with sorbing cationic or anionic species to form surface complexes. The models differ in their descriptions of the electrical double layer and the manners in which changes in the background electrolyte concentration are incorporated in model computations. Titration data for three hydrous oxides, $\alpha$-FeOOH, $\alpha-\mathrm{Al}_{2} \mathrm{O}_{3}$, and $\mathrm{TiO}_{2}$, are used in this analysis of the SCM approach. This work expands upon earlier studies (7-9) of model parameter estimation from titration data, generalizing previous conclusions for a wider range of conditions and systems, and quantifies, for the first time, the range of parameter values that can be used to fit titration data for three different and widely used SCMs.

\section{SURFACE COMPLEXATION MODELS (SCMs)}

The SCMs chosen for evaluating the sensitivity of model simulations to changes in parameter values were the diffuse-layer model (DLM) $(2,4,7,10,11)$, the constant-capacitance model $(\mathrm{CCM})(2,7,12-14)$, and the triple-layer model (TLM) (2-4, 14-16). All have been widely used for describing the surface chemical reactions of oxide minerals (1719). These models differ in complexity from the simplest, DLM, which has three adjustable model parameters, to the most complex, TLM, which has seven adjustable parameters. In the DLM, the three adjustable parameters that can be optimized for simulating titration behavior are the two surface protolysis constants, $K^{+}$,
$K^{-}$, and the total number of surface sites, $N_{\mathrm{t}}$. The four adjustable parameters in the CCM that can be optimized for simulating titration behavior are the two surface protolysis constants, $K^{+}, K^{-}$, the total number of surface sites $N_{\mathrm{t}}$, and an inner-layer capacitance term, $C_{1}$. The more complex TLM has seven adjustable fitting parameters including two surface protolysis constants, $K^{+}, K^{-}$, two capacitance parameters, $C_{1}, C_{2}$, total site concentration, $N_{\mathrm{t}}$, and two electrolyte surface-binding constants, $K_{\text {An }}$ and $K_{\text {Cat }}$.

Table Ia summarizes the three SCMs in terms of the adjustable parameters, the allowed surface chemical reactions, and the chargepotential relationships. Surface charge-balance and mass-balance equations for each of the models are given in Table Ib. Figure 1 depicts the physical-chemical structure of the interfacial region and the interfacial charge and potential relationships for each of these models.

Modeling titration behavior. Titration behavior for each of the SCMs is represented in the following way. For the DLM and CCM,

$$
\begin{aligned}
C_{\mathrm{A}}-C_{\mathrm{B}}=\left(\left[\mathrm{SOH}_{2}^{+}\right]-\left[\mathrm{SO}^{-}\right]\right. \\
\left.+\left[\mathrm{H}^{+}\right]-\left[\mathrm{OH}^{-}\right]\right) .
\end{aligned}
$$

The protolysis reactions are given by

$$
\begin{gathered}
\mathrm{SOH}+\mathrm{H}^{+} \stackrel{K^{+}}{=} \mathrm{SOH}_{2}^{+} \\
\mathrm{SOH} \stackrel{K^{-}}{=} \mathrm{SO}^{-}+\mathrm{H}^{+} \\
\mathrm{H}_{2} \mathrm{O} \stackrel{K_{\mathrm{W}}}{=} \mathrm{H}^{+}+\mathrm{OH}^{-}
\end{gathered}
$$

with the thermodynamic equilibrium constants

$$
\begin{array}{r}
K^{+}=\frac{\left[\mathrm{SOH}_{2}^{+}\right]}{[\mathrm{SOH}]\left[\mathrm{H}^{+}\right]} \exp \left(F \psi_{0} / R T\right) \\
K^{-}=\frac{\left[\mathrm{SO}^{-}\right]\left[\mathrm{H}^{+}\right]}{[\mathrm{SOH}]} \exp \left(-F \psi_{0} / R T\right) \\
K_{\mathrm{W}}=\left[\mathrm{H}^{+}\right]\left(\gamma_{\mathrm{H}^{+}}\right)\left[\mathrm{OH}^{-}\right]\left(\gamma_{\mathrm{OH}^{-}}\right) .
\end{array}
$$


TABLE Ia

Surface Complexation Reactions and Model Parameters

\begin{tabular}{rrr}
\hline DLM & CCM & TLM \\
\hline
\end{tabular}

\section{Protolysis reaction}

$\begin{array}{ll}\mathrm{SOH}+\mathrm{H}^{+}=\mathrm{SOH}_{2}^{+} & K^{+} \\ \mathrm{SOH}=\mathrm{SO}^{-}+\mathrm{H}^{+} & K^{-} \\ & \\ \mathrm{SOH}+\mathrm{Me}^{2+}=\mathrm{SOMe}^{+}+\mathrm{H}^{+} & K_{\mathrm{Me}} \\ \mathrm{SOH}+\mathrm{L}^{-}=\mathrm{SL}+\mathrm{OH}^{-} & K_{\mathrm{L}}\end{array}$
$\mathrm{SOH}+\mathrm{L}^{-}=\mathrm{SL}+\mathrm{OH}^{-} \quad K_{\mathrm{L}}$

Not Allowed

$-\sigma_{0}=\sigma_{\mathrm{d}}=-0.1174 \sqrt{I} \sinh \left(z F \psi_{\mathrm{d}} / 2 R T\right)$ $\psi_{0}=\psi_{\mathrm{d}}$

Adjustable model parameters

$K^{+}, K^{-}, N_{\mathrm{s}}$

$K^{+}, K^{-}, N_{s}, C_{1}$
Same as DLM

\section{Surface complexation reactions}

Coordination Complexes

Same as DLM

Same as DLM

Ion-pair complexes

Not Allowed

$\mathrm{SOH}+\mathrm{Cat}^{+}=\mathrm{SO}^{-}-\mathrm{Cat}^{+}+\mathrm{H}^{+} K_{\mathrm{Cat}}$ $\mathrm{SOH}+\mathrm{An}^{-}+\mathrm{H}^{+}=\mathrm{SOH}_{2}^{+}-\mathrm{An}^{-} K_{\mathrm{An}}$

\section{Charge-potential relationships}

$$
\begin{array}{ll}
\sigma_{0}=C_{1} \psi_{0} & \sigma_{\mathrm{d}}=-0.1174 \sqrt{\mathrm{I}} \sinh \left(z F \psi_{\mathrm{d}} / 2 R T\right) \\
& \sigma_{0}=\left(\psi_{0}-\psi_{\beta}\right) C_{1} \\
& \sigma_{0}+\sigma_{\beta}=\left(\psi_{\beta}-\psi_{\mathrm{d}}\right) C_{2}=-\sigma_{\mathrm{d}}
\end{array}
$$

\footnotetext{
${ }^{a} C_{2}$ usually assumed fixed at $0.2 \mathrm{~F} / \mathrm{m}^{2}$.
}

For the TLM,

$$
\begin{aligned}
\left(C_{\mathrm{A}}-C_{\mathrm{B}}\right)=\left[\mathrm{SOH}_{2}^{+}\right]+\left[\mathrm{SOH}_{2}^{+}-\mathrm{An}^{-}\right] \\
-\left[\mathrm{SO}^{-}\right]-\left[\mathrm{SO}^{-}-\mathrm{Cat}^{+}\right] \\
+\left[\mathrm{H}^{+}\right]-\left[\mathrm{OH}^{-}\right]
\end{aligned}
$$

\begin{tabular}{|c|c|c|}
\hline Model & Surface Charge Balance Equations ${ }^{b}$ & Surface Mass Balance Equations \\
\hline DLM & $\sigma_{0}=B\left(\left[\mathrm{SOH}_{2}^{+}\right]-\left[\mathrm{SO}^{-}\right]\right)$ & $S_{\mathrm{T}}=[\mathrm{SOH}]+\left[\mathrm{SOH}_{2}^{+}\right]+\left[\mathrm{SO}^{-}\right]+[\mathrm{SL}]+\left[\mathrm{SOMe}^{+}\right]$ \\
\hline $\mathrm{CCM}$ & Same as for DLM & Same as for DLM \\
\hline $\mathrm{TLM}^{c}$ & $\begin{aligned} \sigma_{0} & =B\left(\left[\mathrm{SOH}_{2}^{+}\right]+\left[\mathrm{SOH}_{2}^{+}-\mathrm{An}^{-}\right]+\left[\mathrm{SOMe}^{+}\right]\right. \\
& \left.-\left[\mathrm{SO}^{-}\right]-\left[\mathrm{SO}^{-}-\mathrm{Cat}^{+}\right]\right) \\
\sigma_{\beta} & =B\left(\left[\mathrm{SO}^{-}-\mathrm{Cat}^{+}\right]-\left[\mathrm{SOH}_{2}^{+}-\mathrm{An}^{-}\right]\right)\end{aligned}$ & $\begin{array}{l}S_{\mathrm{T}}=[\mathrm{SOH}]+\left[\mathrm{SOH}_{2}^{+}\right]+\left[\mathrm{SO}^{-}\right]+\left[\mathrm{SOH}_{2}^{+}-\mathrm{An}^{-}\right] \\
\quad+\left[\mathrm{SO}^{-}-\mathrm{Cat}^{+}\right]+[\mathrm{SL}]+\left[\mathrm{SOMe}^{+}\right]\end{array}$ \\
\hline
\end{tabular}

$K^{+}, K^{-}, K_{\mathrm{Cat}} K_{\mathrm{An}}, N_{\mathrm{s}}, C_{1}, C_{2}^{a}$

\section{TABLE Ib}

Surface Charge and Mass Balance Equations ${ }^{a}$

\footnotetext{
${ }^{a}$ Equations written for systems described in Table Ia.

${ }^{b}$ The constant, $B$, converts surface charge from mole/liter to $\mathrm{C} / \mathrm{m}^{2} ; B=F / C_{\mathrm{S}} S_{\mathrm{A}}$ where $F$ is Faraday's constant, $C_{\mathrm{S}}$ is the solids concentration in $\mathrm{g} /$ liter, and $S_{\mathrm{A}}$ is the specific surface area of the solid in $\mathrm{m}^{2} / \mathrm{g}$.

${ }^{c}$ Charge balance equation written for each plane. For example, for the surface species $\left[\mathrm{SO}^{-}-\mathrm{Cat}^{+}\right]$, one negative charge in the o-plane and one positive charge in the $\beta$-plane results from each sorbed species.
} 
A

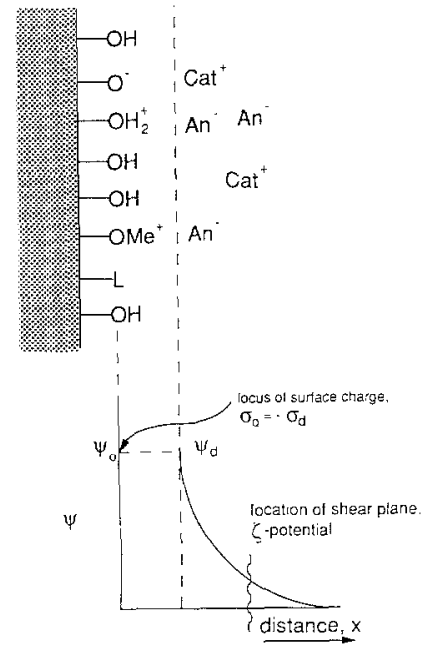

B
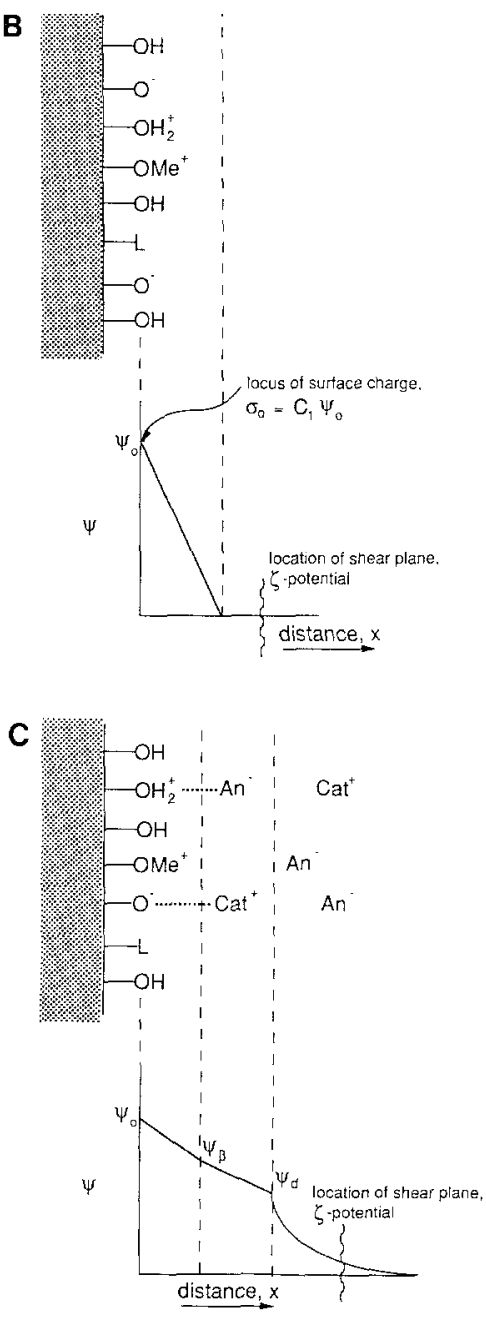

$$
\mathrm{SOH}+\mathrm{Cat}^{+} \stackrel{K_{\text {Cat }}}{=} \mathrm{SO}^{-}-\mathrm{Cat}^{+}
$$

with the associated equilibrium constants

$$
\begin{aligned}
K_{\mathrm{An}}= & \frac{\left[\mathrm{SOH}_{2}^{+}-\mathrm{An}^{-}\right]}{[\mathrm{SOH}]\left[\mathrm{H}^{+}\right]\left[\mathrm{An}^{-}\right]} \\
& \times \exp \left(F\left(\psi_{0}-\psi_{\beta}\right) / R T\right) \\
K_{\mathrm{Cat}}= & \frac{\left[\mathrm{SO}^{-}-\mathrm{Cat}^{+}\right]\left[\mathrm{H}^{+}\right]}{[\mathrm{SOH}]\left[\mathrm{Cat}^{+}\right]} \\
& \times \exp \left(F\left(\psi_{\beta}-\psi_{0}\right) / R T\right) .
\end{aligned}
$$

As can be seen from Eqs. [1]-[12], the DLM and CCM have only one set of surface reactions that can lead to proton consumption or release, defined by $K^{+}$and $K^{-}$, whereas the TLM has two sets of model protolysis or dissociation reactions, defined by $K^{+}, K_{\mathrm{An}}$ and $K^{-}, K_{\text {Cat }}$.

Model calculations of activity coefficients. For aqueous phase reactions such as Eq. [7] above, activity coefficients such as $\gamma_{\mathrm{H}^{+}}$and $\gamma_{\mathrm{OH}^{-}}$are calculated according to the Davies equation. In contrast, the activity coefficients for species involved in surface reactions like Eqs. [5], [6], [11], and [12] are lumped into the exponential interfacial potential terms and are calculated from the model-generated interfacial potentials, based on the standard and references states as defined in Hayes and Leckie (20). All of the models may be used for ionic strengths up to $0.1 M$, the upper limit for using the Davies correction for computing the activity coefficients. However, as described below, based on theoretical consideration, the DLM and CCM are often limited to lower and higher ionic strength conditions, respectively. Modeling effects of ionic strength changes. Although all of the models can be used for a range of ionic strength values, each SCM accounts for changing ionic strength conditions differently. In the DLM, ionic strength effects on protolysis equilibria are accounted for explicitly through the Gouy-Chapman-Stern-

FIG. 1. Schematic representation of the electrical properties of the interfacial region: (A) diffuse-layer model (B) constant capacitance model (C) triple-layer model. 
Grahame (GCSG) charge-potential relationship, which for a 1:1 electrolyte solution is given by

$$
\begin{aligned}
-\sigma_{0} & =\sigma_{\mathrm{d}} \\
& =-0.1174 \sqrt{I} \sinh \left(z F \psi_{\mathrm{d}} / 2 R T\right) .
\end{aligned}
$$

Since the interfacial potential is used in the activity corrections for surface reactions, as described above, and according to Eq. [13] the effects of ionic strength on interfacial potential can be taken into account, in principle, only one set of DLM surface constants should be necessary to model sorption over a range of ionic strength conditions. However, the DLM has usually been restricted to modeling low ionic strength conditions because it has been found to significantly overpredict the diffuse-layer potential at high ionic strengths (19). Dzombak and Morel (19) have recently presented an approach for increasing the range of applicability of the DLM to ionic strengths up to $0.1 \mathrm{M}$.

In contrast to the DLM, the application of the $\mathrm{CCM}$ is restricted to constant ionic strength conditions. This restriction is due to the form of the charge-potential relationship, which for the CCM is given by

$$
\sigma_{0}=C_{1} \psi_{0} .
$$

According to Eq. [14], the interfacial potential is not dependent on ionic strength, and as a result the CCM surface equilibrium constants cannot be corrected for changing ionic strength conditions. Because of this, a different set of CCM surface constants is required for each set of ionic strength conditions to be modeled.

The application of the CCM is also usually limited to high ionic strength conditions. This limitation has been justified based on theoretical considerations. For very small potentials, e.g., less than $25 \mathrm{mV}$ at $25^{\circ} \mathrm{C}$, Eq. [13] reduces to the form (21)

$$
\sigma_{\mathrm{d}}=-\epsilon \kappa \psi_{\mathrm{d}},
$$

where $\kappa$ is the Debye length given by

$$
\kappa=\left(\frac{2000 F^{2}}{\epsilon_{0} \epsilon_{\mathrm{r}} R T}\right)^{1 / 2} \sqrt{I} .
$$

With $C_{1}$ equal to $\epsilon \kappa$, the diffuse layer model of the interface, Eq. [13], reduces to the constant capacitance interfacial model, Eq. [14]. Since low interfacial potentials are usually only found near the point of zero charge, or at higher ionic strengths, the application of the CCM is usually restricted to high ionic strength conditions, greater than $0.01 \mathrm{M}$.

Like the DLM, the TLM can be used to model surface reactions over a range of ionic strength conditions with one set of surface equilibrium constants. The TLM has two ways to account for changes in ionic strength: (i) by allowing ion-pair complexes between the surface sites and background electrolytes, and (ii) through the ionic strength dependence of Eq. [13], which is also incorporated into the description of the interfacial region in the TLM. Allowing surface reactions between the background electrolyte ions and surface hydroxide sites is a unique feature of the TLM compared to the simpler SCMs. Because of the two additional model parameters associated with these reactions, $K_{\mathrm{An}}$ and $K_{\mathrm{Cat}}$, the TLM may be expected to model titration data successfully over a wider range of ionic strengths, compared to the simpler models. The TLM is applicable to systems ranging from near zero to ionic strengths up to $0.1 \mathrm{M}$, the upper limit of applicability of the Davies equation.

\section{MODEL PARAMETER ESTIMATION}

If SCMs are to be used to model sorption processes, experimental or theoretical methods are required to determine the values for the various model parameters. Parameter values which must be evaluated include the total site concentration of the solid, interfacial capacitances, and surface equilibrium constants. For any of these, the preferred method of obtaining the parameter value is to measure it directly. However, except for the total site concentration, this has not been possible. Instead, model parameter values are often selected as a set of values and evaluated as such based on their ability to adequately simulate experimental ti- 
tration data. The best set of values is typically based on a goodness-of-fit criterion. Within this framework, this section summarized current methodologies that are used to estimate SCM parameter values and provides theoretical considerations that can be applied to bracket "reasonable" values for SCM parameters.

For oxide minerals, the total site concentration, $N_{\mathrm{t}}$ (moles/liter) can be calculated from measured values for surface area, $S_{\mathrm{A}}$, site density, $N_{\mathrm{s}}$, and solids concentration, $C_{\mathrm{s}}$ (with units of $\mathrm{m}^{2} / \mathrm{gm}$, sites $/ \mathrm{m}^{2}, \mathrm{gm} /$ liter, respectively) measurements:

$$
N_{\mathrm{t}}=N_{\mathrm{s}} \times S_{\mathrm{A}} \times C_{\mathrm{s}} \times 1.66 \times 10^{-6} .
$$

Surface area and site density values can be determined experimentally from BET surface area (22) and tritium exchange measurements (23), respectively. The site density values for oxides range from 2 to 20 sites $/ \mathbf{n m}^{2}$ (16). Hence, given the surface area and solids concentration, one can determine within an order of magnitude the range of reasonable values for $N_{\mathrm{t}}$, assuming the site density falls within the typical range of 2 to 20 sites $/ \mathrm{nm}^{2}$. For example, in the case of $\alpha$-FeOOH used in this study, with a surface area of $52 \mathrm{~m}^{2} / \mathrm{gm}$ and a solids concentration of $15 \mathrm{~g} /$ liter, the range of reasonable values of $N_{\mathrm{t}}$ would be $2.6 \times 10^{-3}$ to $2.6 \times 10^{-2} M$.

To estimate values for the SCM surface equilibrium constants, acid-base titration data for oxide suspensions are required. The two most common methods for determining surface equilibrium constants from titration data are by using objective curve fitting routines (24) or by graphical extrapolation methods $(16,25,26)$. To determine $\log K^{+}$or $\log K^{-}$ the graphical extrapolation techniques involve plotting an approximation for the conditional protolysis equilibrium constants given by

$$
\mathrm{p} Q^{*}=-\log \left[\mathrm{H}^{+}\right] \pm \log \left(\frac{\alpha}{1-\alpha}\right)
$$

versus the fractional ionization,

$$
\alpha=\frac{\sigma_{0}}{N_{\mathrm{s}}} \times\left(\frac{N_{\mathrm{A}}}{F}\right),
$$

where $\left(N_{\mathrm{A}} / F\right)$ converts $\sigma_{0}$ to net number of charged sites $/ \mathrm{m}^{2}$ to give the dimensionless fractional ionization, $\alpha$. Plotting data according to Eqs. [18] and [19] and extrapolating back to zero fractional ionization for a given ionic strength is the single extrapolation method (15), applicable to all the SCMs. Alternatively, for the TLM, the fractional ionization can be plotted versus some linear combination of the fractional ionization and ionic strength,

$$
\alpha+\sqrt{I}
$$

or

$$
\alpha+\log (I) .
$$

Plotting data according to Eqs. [18] and [20] or [21] and extrapolating to the zero value for Eq. [20] or [21] results in the so-called double extrapolation value for the TLM surface constants $(16,25,26)$. At present, we feel the extrapolation procedures cannot be used conveniently to produce a unique set of surface constants since, (i) there are no objective methods to determine which range of titration data should be used in the extrapolations, (ii) there is no basis for choosing the form of the extrapolation, e.g., linear versus polynomialfit extrapolation of the data, and (iii) the extrapolation methods ensure that a large difference in the protolysis constants (large $\left.\Delta \mathrm{p} K_{\mathrm{A}}\right)$ will be found for all SCMs $(8,27-31)$. In the case of the TLM, where a wide range of $\Delta \mathrm{p} K_{\mathrm{A}}$ values may fit the titration data equally well, these limitations make it especially difficult to use the graphical extrapolation techniques to arrive at a unique set of parameter values.

For the TLM, the determination of the surface constants by any method is further complicated because it is not possible to independently determine the relative contribution of reactions of Eqs. [2], [3] versus [9], [10] to the observed titration behavior modeled by Eq. [8]. One possible method of distinguishing the relative contribution would be to directly measure electrolyte sorption as a function of changing electrolyte concentration and $\mathrm{pH}$. 
This has been attempted by Smit and coworkers $(27,32,33)$ and Sprycha and Szczypka (29, 34, 35). Their results indicate that electrolyte sorption may be somewhat greater than estimates based on the extrapolation techniques. However, because of the difficulty in separating the solid from the liquid phase to quantify electrolyte sorption (which required the use of acetone-water washes in one case (27) and a double-centrifuging method in the other (34)) the results from these studies may not be directly comparable to titration data which are collected under very different conditions, using microcrystalline powders at relatively low solids concentration (10-30 gm/liter).

To date, no method exists for independently measuring electrical double-layer capacitance parameters for oxide-water systems. For the models used in this study, values for the capacitance, $C_{1}$, in the CCM and for the innerand outer-layer capacitance, $C_{1}$ and $C_{2}$, for the TLM are needed. In the TLM, a value for $C_{2}$ of $0.2 \mathrm{~F} / \mathrm{m}^{2}$ is usually assumed, based on direct measurements of the capacitance of the AgI-electrolyte interface (36). However, the applicability of these direct measurements to oxides surfaces is uncertain. Bousse and Bergveld (37), making impedance measurements on $\mathrm{SiO}_{2}$-coated, ion-sensitive field effect transistors, support the $C_{2}$ value of $0.2 \mathrm{~F} / \mathrm{m}^{2}$ for oxides. Others, however, suggest the value for $C_{2}$ should be somewhat lower $(38,39)$. No method has been found yet that can be used to directly measure $C_{1}$. Some researchers have suggested that values for $C_{1}$ can be obtained from titration data $(27,34)$. However, the subjective assumptions inherent in the extrapolation methods as described above remain when one attempts to obtain capacitance values from the slopes of data plotted according to Eqs. [17]-[20] (8). Hence, $C_{1}$ should be considered a fitting parameter.

At present, subjective choices, based on theoretical considerations of a given model and curve fitting routines, provide a simpler, more consistent way for selecting the values of the capacitance parameters. The range of capacitance values which satisfies the theoretical framework of the various models can be calculated from the definition of the integral capacitance (40):

$$
C_{1}=\frac{\epsilon_{\mathrm{r}} \epsilon_{0}}{\beta}
$$

Given that the range of reasonable values for $\epsilon_{\mathrm{r}}$ in the double-layer region is from 6 (dielectric saturation ) to 50 (13), and that the distance of closest approach of a hydrated radius of a univalent ion is in the range of 2.3 to 4.3 $\AA$ (39), $C_{1}$ should not be outside the range of 0.1 to $2.0 \mathrm{~F} / \mathrm{m}^{2}$. If the capacitance values required to fit the titration data fall outside this range, then it is likely that the premises on which the models have been developed are no longer valid.

In this study, we have used the nonlinear, least-squares fitting program, FITEQL (24), to find optimum model parameter values from a set of titration data. This program optimizes the values of adjustable parameters by changing their values until the sum of the squares of the residuals between the measured titration data and FITEQL calculated values is minimized. Optimization can be performed using titration data at a single ionic strength, or data from multiple ionic strength values. In general, FITEQL convergence is most likely to occur when fitting data using only two adjustable parameters. In fact, for the TLM, FITEQL will never converge if the protolysis constants and electrolyte binding constants are simultaneously declared as adjustable parameters, a consequence of interdependence of these surface reactions.

\section{POTENTIOMETRIC TITRATION DATA}

Materials. The titration data for three oxides, $\mathrm{TiO}_{2}, \alpha$-FeOOH, and $\alpha-\mathrm{Al}_{2} \mathrm{O}_{3}$, were used in the sensitivity analysis. $\mathrm{TiO}_{2}$ titration data were obtained from the study by Yates (23). The BET $\mathrm{N}_{2}$ surface area reported for this material was $20 \mathrm{~m}^{2} / \mathrm{gm}$ (23). $\alpha$-FeOOH was syn- 
thesized according to the method of Atkinson et al. (41) while $\alpha-\mathrm{Al}_{2} \mathrm{O}_{3}$ with a reported average particle size of $1.0 \mu \mathrm{m}$ was obtained from Buehler LTD (Evanston, IL). Both $\alpha$-FeOOH and $\alpha-\mathrm{Al}_{2} \mathrm{O}_{3}$ were acid and base washed with $\mathrm{CO}_{2}$-free Milli-Q water to remove surface impurities. Following the acid-base washing, the solids were rinsed by continuously pumping $\mathrm{CO}_{2}$-free Milli-Q water through a suspension of solid contained in an Amicon M2000 ultrafiltration system with an XM300 membrane (having a $300,000 \mathrm{~mol} w \mathrm{w}$ cutoff). The solid suspension was rinsed until the effluent water had the conductivity of the influent Milli-Q water (ca. $1.0 \times 10^{-7} \Omega^{-1} / \mathrm{cm}$ ). The solids were subsequently freeze-dried and stored in a vacuum desiccator. The BET surface areas of $\alpha-\mathrm{FeOOH}$ and $\alpha-\mathrm{Al}_{2} \mathrm{O}_{3}$ were 52 $\mathrm{m}^{2} / \mathrm{gm}$ and $12 \mathrm{~m}^{2} / \mathrm{gm}$, respectively. The surface areas reported here along with assumed values for the site density were used to calculate $N_{\mathrm{t}}$ according to Eq. [16].

Titration data. The potentiometric titration experiments for $\alpha-\mathrm{FeOOH}$ and $\alpha-\mathrm{Al}_{2} \mathrm{O}_{3}$ were carried out as follows. Dried solid samples were suspended in deionized, argon-purged water for at least 2 days prior to the titrations. The aged suspensions were then placed in water-jacketed reactors to maintain the temperature at $25^{\circ} \mathrm{C}$ and stirred to prevent settling, while an argon atmosphere was maintained at all times. Electrolyte was added to adjust the ionic strength to the lowest level to be studied. Acid was added gradually to lower the $\mathrm{pH}$ to an arbitrary starting value at least $2 \mathrm{pH}$ units away from the point of zero salt effect (PZSE), the crossover point of a family of constant ionic-strength titration curves (16). Then the titration was carried out by adding incremental volumes of base. Between each incremental addition, 2-10 min were allowed for $\mathrm{pH}$ equilibration. The final $\mathrm{pH}$ of the base titration never exceeded 11 , in order to minimize dissolution. A reverse acid titration was performed to return the suspension to the original starting $\mathrm{pH}$. Additional electrolyte was then added to adjust the ionic strength to the next higher level desired, and the titration was re- peated following the same protocol. Typically, titrations for at least three ionic strength conditions, varying over two orders of magnitude, were performed for each solid. Based on extensive titration studies, no significant hysteresis was observed between acid and base titration "legs" using the above approach. Only the base leg of the titration has been reported here and included in this analysis.

\section{SENSITIVITY ANALYSIS}

In this sensitivity analysis, two types of information were sought: (i) the range of values for a given input model parameter that would result in FITEQL convergence leading to reasonable fits to the titration data, and (ii) the effect that preselected values of model input parameters would have on the FITEQL, bestfit, values for the "adjustable parameters," i.e., those parameters that are adjusted during execution of FITEQL until the convergence criterion is met. Because each SCM has a different number of adjustable parameters, slightly different sensitivity analysis strategies were implemented for each model.

DLM sensitivity analysis. In the case of the DLM, which has three adjustable model parameters $\left(\log K^{+}, \log K^{-}\right.$and $N_{\mathrm{s}}$ ), the sensitivity analysis was conducted by varying the value of $N_{\mathrm{s}}$ (for a given solids concentration and surface area) in the FITEQL input file and observing the effect on the optimized values of $\log K^{+}$and $\log K^{-}$. Because the DLM can explicitly account for changes in the concentration of background electrolyte by Eq. [13], two types of data sets were analyzed: (i) individual ionic-strength titration data sets, and (ii) combined ionic-strength titration data sets.

$C C M$ sensitivity analysis. For the CCM, which has four adjustable model parameters $\left(\log K^{+}, \log K^{-}, N_{\mathrm{s}}\right.$, and $\left.C_{1}\right)$, the sensitivity analysis was performed by systematically changing the values $C_{1}$ and $N_{\mathrm{s}}$ in the FITEQL input file and observing the effects on the bestfit values of $\log K^{+}$and $\log K^{-}$. Since the CCM parameter values are only valid for con- 
stant ionic strength conditions, the sensitivity analysis was confined to the analysis of titration data sets at single ionic strengths.

TLM sensitivity analysis. In the case of the TLM, (with six adjustable parameters, $\log K^{+}, \log K^{-}, N_{\mathrm{s}}, C_{1}$, and $\log K_{\text {An }}$, $\log K_{\text {Cat }}$ ), a slightly different sensitivity analysis approach was performed. $C_{2}$ was assumed to be $0.2 \mathrm{~F} / \mathrm{m}^{2}$ as has been done by others ( 7 , 15). Because of the larger number of parameters in the TLM, additional constraints had to be employed to allow the sensitivity analysis to be performed in a systematic way. The relationship

$$
\frac{\left(\log K^{+}-\log K^{-}\right)}{2}=\mathrm{pH}_{\mathrm{PZSE}}
$$

was used to reduce the degrees of freedom by one. For example, if the $\mathrm{pH}_{\mathrm{PZSE}}=7.0$ and $\log K^{+}$is chosen as 6 , then this requires the value of $\log K^{-}$to be -8 . The assumed absence of specifically adsorbing ions other than the proton requires that Eq. [23] be valid. For TLM sensitivity analysis, the values of $N_{\mathrm{s}}, C_{1}$, and $\Delta \mathrm{p} K_{\mathrm{a}}$ (defined as $-\left[\left(\log K^{+}\right)\right.$ $\left.\left.+\left(\log K^{-}\right)\right]\right)$were systematically varied, one variable at a time, in the FITEQL input file and the best-fit values of $\log K_{\mathrm{An}}$ and $\log K_{\text {Cat }}$ were obtained by FITEQL.

Since the TLM incorporates the effects of background electrolyte concentration on titration behavior directly in model calculations, both single ionic-strength titration data sets and combined ionic-strength titration data sets were used in the sensitivity analysis.

Quality and extent of titration data. In a few selected systems, the effects of the data point distribution and the $\mathrm{pH}$ range of titration data sets on the FITEQL best-fit values of the adjustable parameters were evaluated. This was done by selecting subsets of data points from a titration curve and observing differences in the values of the optimized constants and the goodness of fit.

Estimation of the goodness of fit. For the purposes of analyzing the quality of the fit, a goodness-of-fit parameter, $F$, defined as

$$
F=\frac{\sum\left(Y_{i} / s_{i}\right)^{2}}{N_{p} \times N_{c}-N_{u}},
$$

was used (16). The numerator of Eq. [24] is the sum of the squares of the residuals for each data point, $Y_{\mathrm{i}}$, divided by the error estimate for each titration data point, $s_{\mathrm{i}}$. The denominator is the number of degrees of freedom calculated as the number of titration data points, $N_{\mathrm{p}}$, times the number of components for which both the total and the free concentration are known, $N_{\mathrm{c}}$, minus the number of adjustable parameters, $N_{\mathrm{u}}$. In general, lower values of $F$ indicate better fits to the data. Since the goodness-of-fit value, $F$, depends on the absolute and relative error values $\left(s_{i}\right)$ estimated for the titration data points, $F$ values reported, unless otherwise noted, are for cases where the same error values in the titration data have been assumed. Because the sum of the squares of the residuals for each data point are divided by $s_{\mathrm{i}}$, the higher the assumed values of error in the titration data points, the lower are the resulting goodness-of-fit values, $F$. In the cases of model computations reported here, the only component for which both the total and free concentration were known was the proton. Hence, $N_{\mathrm{c}}$ was always equal to 1 . Regardless of the model (DLM, CCM, or TLM), the number of adjustable parameters, $N_{\mathrm{u}}$ was always equal to 2 . As a result, the only difference in the degrees of freedom among titration data sets was the number of data points. Based on the above formula for $F$, titration data sets for a given solid having more points should result in a proportionately smaller value of $F$, assuming the data are all measured with equal accuracy and precision.

In all FITEQL runs reported, unless otherwise noted, the assumed absolute and relative error of the titration data points were chosen to be representative of those errors expected in titration experiments. Typical values for relative and absolute errors were 0.01 and $2.0 \times 10^{-8} M$, respectively, for total proton concentrations, and 0.05 and 0.0 , respectively, for $\left[\mathrm{H}^{+}\right]$. The relative error for total proton concentration is based on the volumetric di- 
lution error associated with preparing stock solutions of acids and bases (1\% assumed). The absolute error is estimated from the minimum incremental titrant addition of 0.0002 $\mathrm{ml}$ and titrant normality of $0.1 M$. Absolute errors in $\mathrm{pH}$ (logarithmic concentrations) become relative errors in hydrogen ion concentration. The relative and absolute errors in the hydrogen ion concentration are based on an assumed absolute error in the measurement of $\mathrm{pH}$ of 0.02 (24). In some selected cases, the effects of the values assumed for the $a b$ solute and relative errors were also evaluated.

\section{SENSITIVITY ANALYSIS RESULTS}

The sensitivity analysis results for DLM, CCM, and TLM computations are summarized below. Since the purpose of this work was to evaluate the relative merits of each model, the results are divided into individual sections for each model.

$D L M$. In the case of the DLM sensitivity analysis, the effects of changes of $N_{\mathrm{s}}$ (from 1 to $100 \mathrm{sites} / \mathrm{nm}^{2}$ ) on the best-fit values of the surface protolysis constants were evaluated (Table II; Fig. 2). The FITEQL best-fit values for $\log K^{+}$and $\log K^{-}$decreased with increasing values of $N_{\mathrm{s}}$ for all titration data sets analyzed. This trend was expected. In order for the computed number of protons released or consumed at a given $\mathrm{pH}$ to fit the titration data for different values of $N_{\mathrm{s}}$ it is necessary that the surface constants decrease as $N_{\mathrm{s}}$ increases. For the $\alpha-\mathrm{Al}_{2} \mathrm{O}_{3}$ and $\alpha-\mathrm{FeOOH}$ data sets, based on the $F$ values, slightly better fits were obtained for $N_{\mathrm{s}}$ less than 10 sites $/ \mathrm{nm}^{2}$ compared to the fits obtained for $N_{\mathrm{s}}$ between 10 and 100 sites $/ \mathrm{nm}^{2}$.

In all cases, better fits (lower $F$ values) were obtained when titration data for one ionic strength was used than when combined ionic strength titration data sets were evaluated. In the DLM, only one adjustable parameter value can influence the shape of the titration curve on either side of the $\mathrm{pH}_{\mathrm{PZSE}}\left(\log K^{+}\right.$at $\mathrm{pH}$ values below and $\log K^{-}$at $\mathrm{pH}$ values above the $\mathrm{pH}_{\mathrm{PZSE}}$ ), so it is not surprising that the fits
TABLE II

Sensitivity of DLM to Variations in Total Site Density

\begin{tabular}{|c|c|c|c|c|c|}
\hline Solid & I.S. ${ }^{a}$ & $N_{\mathrm{s}}^{b}$ & $\log K^{+}$ & $\log K^{-}$ & $F$ \\
\hline$\alpha-\mathrm{FeOOH}$ & CIS $^{c}$ & 1 & 8.59 & -8.82 & 172 \\
\hline$\alpha-\mathrm{FeOOH}$ & CIS & 10 & 7.10 & -10.24 & 201 \\
\hline$\alpha-\mathrm{FeOOH}$ & CIS & 100 & 6.07 & -11.26 & 202 \\
\hline$\alpha$-FeOOH & 0.005 & 1 & N.C. ${ }^{d}$ & N.C. & N.C. \\
\hline$\alpha-\mathrm{FeOOH}$ & 0.005 & 10 & 7.71 & -10.07 & 182 \\
\hline$\alpha-\mathrm{FeOOH}$ & 0.005 & 100 & 6.67 & -11.12 & 182 \\
\hline$\alpha-\mathrm{FeOOH}$ & 0.028 & 1 & 8.88 & -8.31 & 44.8 \\
\hline$\alpha-\mathrm{FeOOH}$ & 0.028 & 10 & 7.14 & -10.00 & 58.4 \\
\hline$\alpha-\mathrm{FeOOH}$ & 0.028 & 100 & 6.11 & -11.03 & 59.1 \\
\hline$\alpha-\mathrm{FeOOH}$ & 0.087 & 1 & 8.20 & -8.74 & 5.71 \\
\hline$\alpha$-FeOOH & 0.087 & 10 & 6.72 & -10.18 & 29.9 \\
\hline$\alpha$-FeOOH & 0.087 & 100 & 5.69 & -11.21 & 31.7 \\
\hline$\alpha-\mathrm{Al}_{2} \mathrm{O}_{3}$ & CIS & 1 & 8.62 & -9.82 & 119 \\
\hline$\alpha-\mathrm{Al}_{2} \mathrm{O}_{3}$ & CIS & 10 & 7.29 & -11.13 & 162 \\
\hline$\alpha-\mathrm{Al}_{2} \mathrm{O}_{3}$ & CIS & 100 & 6.28 & -12.14 & 163 \\
\hline$\alpha-\mathrm{Al}_{2} \mathrm{O}_{3}$ & 0.005 & 1 & 9.04 & -10.00 & 18.9 \\
\hline$\alpha-\mathrm{Al}_{2} \mathrm{O}_{3}$ & 0.005 & 10 & 7.75 & -11.32 & 24.5 \\
\hline$\alpha-\mathrm{Al}_{2} \mathrm{O}_{3}$ & 0.005 & 100 & 6.73 & -11.23 & 24.9 \\
\hline$\alpha-\mathrm{Al}_{2} \mathrm{O}_{3}$ & 0.030 & 1 & 8.80 & -9.13 & 25.0 \\
\hline$\alpha-\mathrm{Al}_{2} \mathrm{O}_{3}$ & 0.030 & 10 & 7.33 & -10.59 & 39.2 \\
\hline$\alpha-\mathrm{Al}_{2} \mathrm{O}_{3}$ & 0.030 & 100 & 6.30 & -11.61 & 40.2 \\
\hline$\alpha-\mathrm{Al}_{2} \mathrm{O}_{3}$ & 0.139 & 1 & 8.37 & -9.24 & 15.0 \\
\hline$\alpha-\mathrm{Al}_{2} \mathrm{O}_{3}$ & 0.139 & 10 & 6.94 & -10.63 & 52.8 \\
\hline$\alpha-\mathrm{Al}_{2} \mathrm{O}_{3}$ & 0.139 & 100 & 5.92 & -11.65 & 55.1 \\
\hline $\mathrm{TiO}_{2}$ & CIS & 1 & 4.99 & -6.80 & 29.2 \\
\hline $\mathrm{TiO}_{2}$ & CIS & 10 & 3.86 & -7.94 & 29.7 \\
\hline $\mathrm{TiO}_{2}$ & CIS & 100 & 2.85 & -8.95 & 29.8 \\
\hline $\mathrm{TiO}_{2}$ & 0.001 & 1 & 4.76 & -6.83 & 0.65 \\
\hline $\mathrm{TiO}_{2}$ & 0.001 & 10 & 3.65 & -7.95 & 0.72 \\
\hline $\mathrm{TiO}_{2}$ & 0.001 & 100 & 2.64 & -8.96 & 0.74 \\
\hline $\mathrm{TiO}_{2}$ & 0.010 & 1 & 5.23 & -6.69 & 0.60 \\
\hline $\mathrm{TiO}_{2}$ & 0.010 & 10 & 4.05 & -7.87 & 0.80 \\
\hline $\mathrm{TiO}_{2}$ & 0.010 & 100 & 3.04 & -8.88 & 0.82 \\
\hline $\mathrm{TiO}_{2}$ & 0.100 & 1 & 6.79 & -5.48 & 2.54 \\
\hline $\mathrm{TiO}_{2}$ & 0.100 & 10 & 4.84 & -7.43 & 2.56 \\
\hline $\mathrm{TiO}_{2}$ & 0.100 & 100 & 3.81 & -8.50 & 2.56 \\
\hline
\end{tabular}

${ }^{a}$ Ionic strength in mol/liter.

${ }^{b}$ Site density in sites per $\mathrm{nm}^{2}$.

${ }^{c}$ Combined ionic-strength case. Constants calculated for best fit over 3 ionic strengths as follows: $0.005,0.028$, and $0.087 M$ for $\alpha-\mathrm{FeOOH} ; 0.005,0.030$, and $0.139 M$ for $\alpha$ $\mathrm{Al}_{2} \mathrm{O}_{3}$; and $0.001,0.010$, and $0.100 M$ for $\mathrm{TiO}_{2}$.

${ }^{d}$ No convergence in numeric scheme.

become poorer when an attempt is made to model a wider range of ionic strengths.

Based on the $F$ value, the DLM best fits to the $\mathrm{TiO}_{2}$ titration data were better than those 

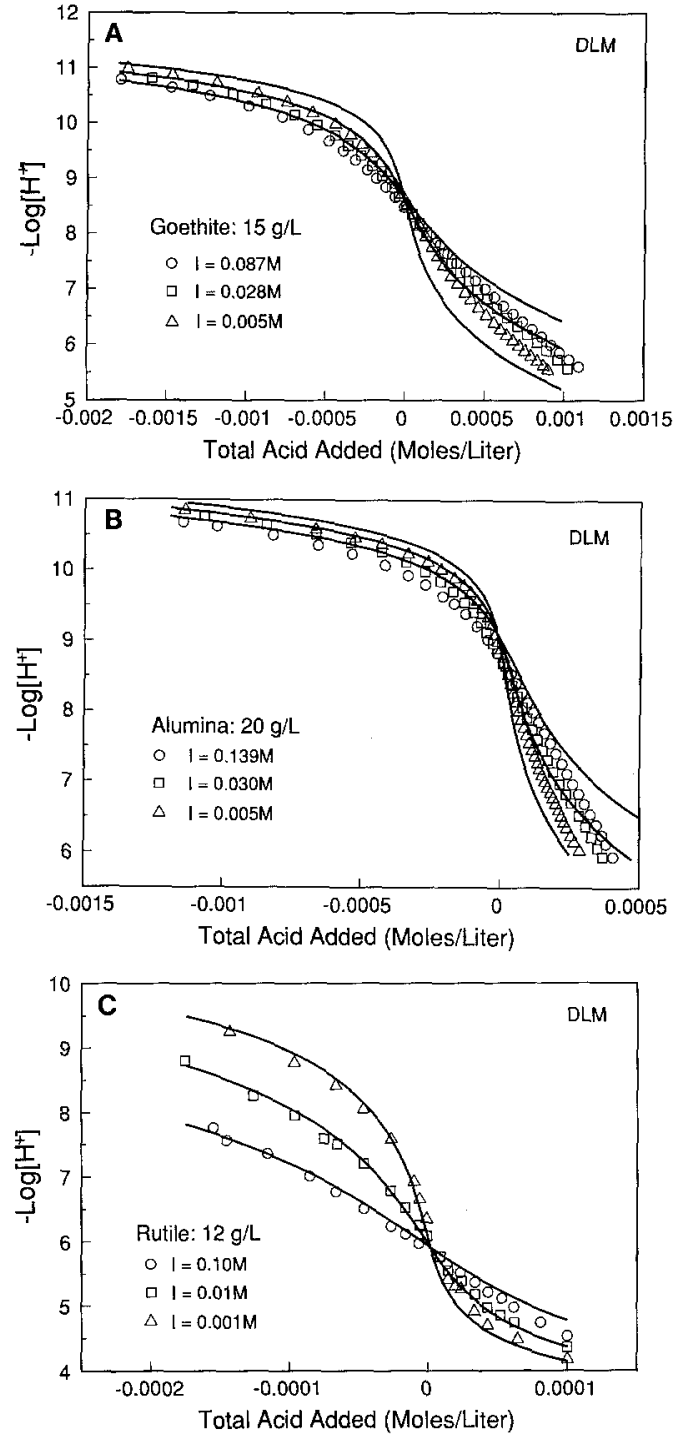

FIG. 2, Diffuse-layer model fits of titration data for suspensions of (A) $\alpha-\mathrm{FeOOH}$, (B) $\alpha-\mathrm{Al}_{2} \mathrm{O}_{3}$, and (C) $\mathrm{TiO}_{2}$ at various $\mathrm{NaNO}_{3}$ concentrations. Values for the parameters used in the model simulations are given in Table VI.

for either $\alpha-\mathrm{Al}_{2} \mathrm{O}_{3}$ or $\alpha-\mathrm{FeOOH}$ regardless of whether single or combined ionic-strength data sets were used in the analysis (Table II). It is not immediately obvious why the DLM fits to the $\mathrm{TiO}_{2}$ data should be better. A comparison of the titration data sets (Figs. 2-4) shows that both the $\alpha-\mathrm{Al}_{2} \mathrm{O}_{3}$ or $\alpha-\mathrm{FeOOH}$ titration data sets have about twice as many points. But the number of data points is not likely the cause of these differences because (i) as discussed above, the $F$ value should actually increase with decreasing number of data points according to Eq. [24], assuming the data are not being removed from a portion of the titration curve where the residuals are largest; and (ii), as shown below in the section describing the effects of the density and number of data points on the fits to titration curves, the number of points apparently have very little influence on the $F$ value when as many as half the titration data points are selectively removed. Based on these considerations, the most logical explanation for the ability of the DLM to fit $\mathrm{TiO}_{2}$ data better than $\alpha-\mathrm{Al}_{2} \mathrm{O}_{3}$ or $\alpha-\mathrm{FeOOH}$ is that there are significant differences in the shapes and positions of the titration curves as a function of ionic strength. In particular, it appears that ionic strength affects $\mathrm{TiO}_{2}$ protolysis more than $\alpha-\mathrm{Al}_{2} \mathrm{O}_{3}$ or $\alpha$ $\mathrm{FeOOH}$ (note the greater relative shift in the titration curves as a function of ionic strength for $\mathrm{TiO}_{2}$ compared to $\alpha-\mathrm{Al}_{2} \mathrm{O}_{3}$ or $\alpha$-FeOOH data). While the surface chemical reasons for these differences are not known at this time, it is possible that dissolution is occurring to a greater extent or that there is a greater concentration of specifically sorbing contaminants (e.g., carbonate) in the $\alpha-\mathrm{Al}_{2} \mathrm{O}_{3}$ or $\alpha-\mathrm{FeOOH}$ systems compared to the $\mathrm{TiO}_{2}$ system. Either of these explanations might account for the differences in the shapes of the titration curves and the apparent reduction in the effects of ionic strength on titration behavior. Another possibility is that the shapes and ionic-strength dependent shifts of the titration curve are a result of more complex surface chemistry for the $\alpha-\mathrm{Al}_{2} \mathrm{O}_{3}$ or $\alpha$-FeOOH systems compared to $\mathrm{TiO}_{2}$ and simply cannot be well represented by the simple DLM. Regardless, these differences point to the potential shortcomings of the DLM for representing wide ranging variation of titration behavior as a function of ionic strength.

The overall conclusion of the sensitivity of the DLM to changes in $N_{\mathrm{s}}$ is that a wide range of values of the site density can give equally 
good fits to the titration data. However, if the range of site density values is limited to values typical of nonporous microcrystalline oxides, 2 to 20 sites $/ \mathrm{nm}^{2}$ (16), then the range for acceptable values for surface protolysis constants is actually quite small, on the order of $0.5 \mathrm{log}$ units. This implies that given a reasonably accurate measurement of site density or assuming a reasonable value, one should be able to arrive at a unique set of surface constants for the DLM using FITEQL and titration data.

$C C M$. In the case of the CCM, the effects of changes of $N_{\mathrm{s}}$ and $C_{1}$ on the best-fit values of the surface protolysis constants were evaluated. The results are summarized in Fig. 3 and the representative trends illustrated for $\alpha$ FeOOH in Table IIIa and IIIb. The effect of $N_{\mathrm{s}}$ on the best-fit values of the surface protolysis constants was the same as that observed for the DLM computations, viz., for a given value of $C_{1}$ and ionic strength, $\log K^{+}$and $\log K^{-}$ decreased with increasing $N_{\mathrm{s}}$. For a given $N_{\mathrm{s}}$ and ionic strength, $\log K^{+}$and $\log K^{-}$decreased with increasing $C_{1}$. If the interfacial region is viewed as a parallel-plate capacitor, this can be explained by greater screening by counterion charge as the values of $C_{1}$ increase. In terms of fitting the titration data, the values of the protolysis constants have to decrease in order to compensate for the effective increase in acidity (proton release) which results from enhanced charge screening as $C_{1}$ increases.

For a given value of $C_{1}$ and $N_{\mathrm{s}}$, as the ionic strength of the data sets increased, so too did the optimized values of $\log K^{+}$and $\log K^{-}$. Since the CCM must be calibrated at each ionic strength, the only way to compensate for the increasing proton or hydroxyl release resulting from increasing ionic strength is for the protolysis constants to increase. The protolysis constants generated using the $\mathrm{CCM}$ resulted in reasonable model fits $(F<20)$ for a wide range of $N_{\mathrm{s}}$ ( 1 to 100 sites $/ \mathrm{nm}^{2}$ ) and $C_{1}$ $\left(0.6\right.$ to $\left.2.0 \mathrm{~F} / \mathrm{m}^{2}\right)$ values. This was the case for all ionic strengths and each oxide evaluated. In general, the CCM did not converge for $C_{1}$ values below $0.6 \mathrm{~F} / \mathrm{m}^{2}$ and the $F$ values got progressively larger for $C_{1}$ values above
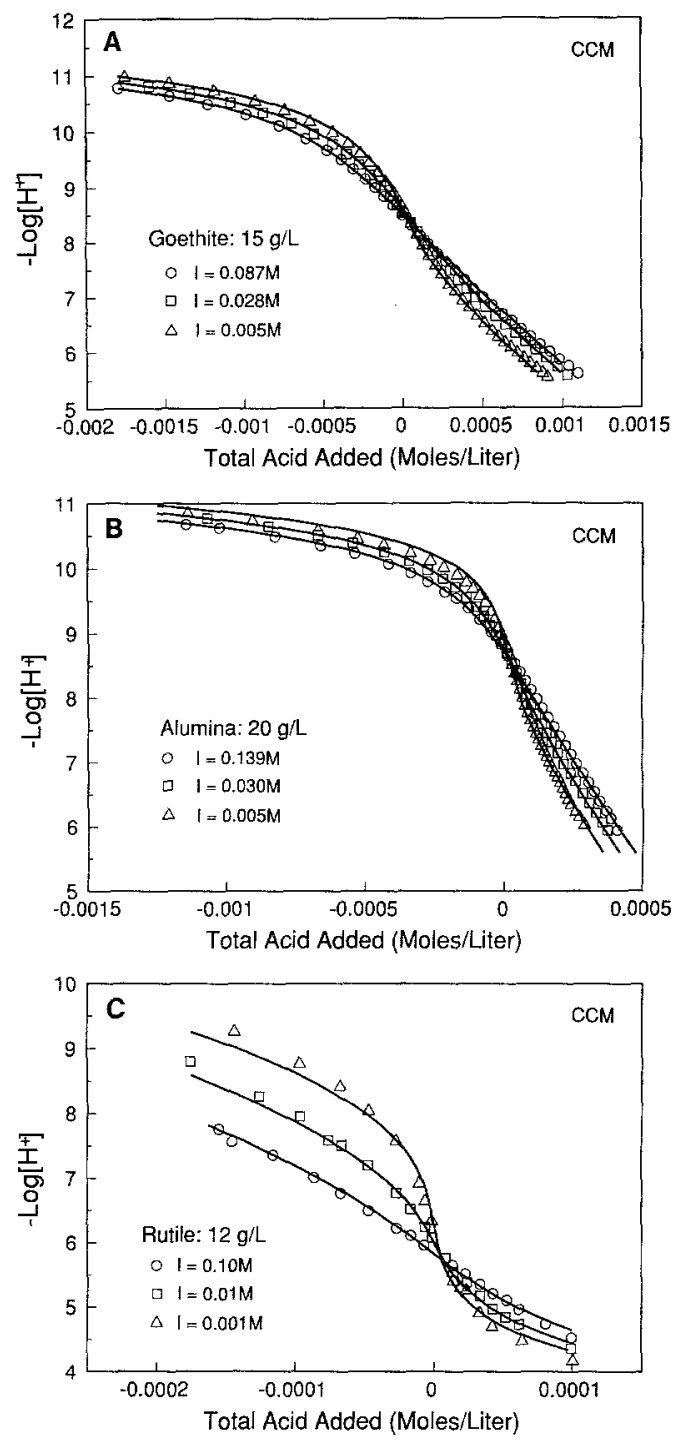

FIG. 3. Constant capacitance model fits of titration data suspensions of (A) $\alpha-\mathrm{FeOOH}$, (B) $\alpha-\mathrm{Al}_{2} \mathrm{O}_{3}$, and (C) $\mathrm{TiO}_{2}$ at various $\mathrm{NaNO}_{3}$ concentrations. Values for the parameters used in the model simulations are given in Table VI.

$1.2 \mathrm{~F} / \mathrm{m}^{2}$. The fits were slightly better for the $\mathrm{TiO}_{2}$ titration data sets. As was the case with the DLM, FITEQL can also be used to extract a unique set of parameter values, if a reasonable value for $N_{\mathrm{s}}$ is chosen or measured and a value for $C_{1}$ specified. While the choice of $C_{1}$ is arbitrary, we support, in absence of any good reason to choose a different value, adopting a 


\section{TABLE IIIa}

Representative Sensitivity of CCM to Variations in Site Density, Ionic Strength, and Capacitance Using $\alpha-\mathrm{FeOOH}$ Titration Data

\begin{tabular}{rrrrrr}
\hline I.S. & \multicolumn{1}{c}{$N_{s}^{b}$} & $C_{1}{ }^{c}$ & Log $K^{+}$ & Log $K^{-}$ & \multicolumn{1}{c}{$F$} \\
\hline 0.005 & 1 & 0.8 & 7.7 & -9.6 & 30.6 \\
0.005 & 1 & 1.0 & 7.4 & -9.8 & 12.3 \\
0.005 & 1 & 1.2 & 7.3 & -10.0 & 4.9 \\
0.005 & 10 & 0.8 & 6.5 & -10.8 & 11.1 \\
0.005 & 10 & 1.0 & 6.2 & -11.0 & 2.8 \\
0.005 & 10 & 1.2 & 6.1 & -11.1 & 10.6 \\
0.005 & 100 & 0.8 & 5.5 & -11.8 & 10.2 \\
0.005 & 100 & 1.0 & 5.2 & -12.0 & 3.0 \\
0.005 & 100 & 1.2 & 5.1 & -12.1 & 12.1 \\
0.028 & 1 & 0.8 & 8.5 & -8.6 & 19.3 \\
0.028 & 1 & 1.0 & 7.8 & -9.3 & 15.4 \\
0.028 & 1 & 1.2 & 7.6 & -9.5 & 7.4 \\
0.028 & 10 & 0.8 & 6.9 & -10.2 & 10.4 \\
0.028 & 10 & 1.0 & 6.6 & -10.6 & 1.7 \\
0.028 & 10 & 1.2 & 6.4 & -10.7 & 2.1 \\
0.028 & 100 & 0.8 & 5.9 & -11.2 & 9.9 \\
0.028 & 100 & 1.0 & 5.5 & -11.6 & 1.3 \\
0.028 & 100 & 1.2 & 5.3 & -11.7 & 2.7 \\
0.087 & 1 & 0.8 & N.C. ${ }^{d}$ & N.C. & N.C. \\
0.087 & 1 & 1.0 & 8.2 & -8.7 & 12.2 \\
0.087 & 1 & 1.2 & 7.8 & -9.1 & 9.5 \\
0.087 & 10 & 0.8 & 7.5 & -9.5 & 5.7 \\
0.087 & 10 & 1.0 & 6.8 & -10.2 & 1.8 \\
0.087 & 10 & 1.2 & 6.5 & -10.4 & 0.3 \\
0.087 & 100 & 0.8 & 6.4 & -10.6 & 5.7 \\
0.087 & 100 & 1.0 & 5.7 & -11.2 & 1.4 \\
0.087 & 100 & 1.2 & 5.5 & -11.4 & 0.6 \\
\hline & & & & &
\end{tabular}

${ }^{a}$ Ionic strength in $\mathrm{mol} / \mathrm{liter}$.

${ }^{b}$ Site density in sites per $\mathrm{nm}^{2}$.

${ }^{c}$ Inner-layer capacitance in $\mathrm{F} / \mathrm{m}^{2}$.

${ }^{d}$ No convergence in numeric scheme.

value of $1.0 \mathrm{~F} / \mathrm{m}^{2}$ for $\mathrm{CCM}$ simulations unless another value gives substantially better fits. Although the CCM was found to fit ionicstrength data below $0.01 M$, it should be remembered that application of the CCM to low ionic-strength conditions requires applying this model outside the range that is justified based on the theoretical considerations described previously.

$T L M$. For the TLM sensitivity analysis, the effects of changes of $N_{\mathrm{s}}, C_{1}$, and $\Delta \mathrm{p} K_{\mathrm{a}}$ on the best-fit values of the electrolyte surface reac- tion constants were evaluated. The results are summarized in Tables IVa, IVb, and V and representative trends illustrated with $\alpha$ FeOOH titration data in Fig. 4.

Increasing the value of $N_{\mathrm{s}}$ resulted in decreasing values of $\log K_{\mathrm{An}}, \log K_{\mathrm{Cat}}$ for all of the titration data sets. As explained above for the DLM and the CCM, in order for the computed number of protons released or consumed at a given $\mathrm{pH}$ to fit the titration data for different values of $N_{\mathrm{s}}$ it is necessary that the surface constants decrease as $N_{\mathrm{s}}$ increases.

\section{TABLE IIIb}

Representative Sensitivity of CCM to Variations in Ionic Strength and Capacitance Using $\alpha$-FeOOH Titration Data

\begin{tabular}{|c|c|c|c|c|c|}
\hline 1.S. ${ }^{a}$ & $N_{\mathrm{s}}^{b}$ & $C_{1}{ }^{c}$ & $\log K^{+}$ & $\log K^{-}$ & $F$ \\
\hline 0.005 & 10 & 0.4 & N.C. ${ }^{d}$ & N.C. & N.C. \\
\hline 0.005 & 10 & 0.6 & 7.0 & -10.1 & 36.0 \\
\hline 0.005 & 10 & 0.8 & 6.5 & -10.8 & 11.1 \\
\hline 0.005 & 10 & 1.0 & 6.2 & -11.0 & 2.8 \\
\hline 0.005 & 10 & 1.2 & 6.1 & -11.1 & 10.6 \\
\hline 0.005 & 10 & 1.4 & 6.0 & -11.2 & 26.8 \\
\hline 0.005 & 10 & 1.6 & 5.9 & -11.2 & 47.1 \\
\hline 0.005 & 10 & 1.8 & 5.8 & -11.3 & 68.9 \\
\hline 0.005 & 10 & 2.0 & 5.7 & -11.3 & 90.9 \\
\hline 0.028 & 10 & 0.4 & N.C. & N.C. & N.C. \\
\hline 0.028 & 10 & 0.6 & N.C. & N.C. & N.C. \\
\hline 0.028 & 10 & 0.8 & 6.9 & -10.2 & 10.4 \\
\hline 0.028 & 10 & 1.0 & 6.6 & -10.6 & 1.7 \\
\hline 0.028 & 10 & 1.2 & 6.4 & -10.7 & 2.1 \\
\hline 0.028 & 10 & 1.4 & 6.2 & -10.8 & 10.2 \\
\hline 0.028 & 10 & 1.6 & 6.1 & -10.9 & 22.7 \\
\hline 0.028 & 10 & 1.8 & 6.0 & -11.0 & 37.6 \\
\hline 0.028 & 10 & 2.0 & 6.0 & -11.0 & 53.4 \\
\hline 0.087 & 10 & 0.4 & N.C. & N.C. & N.C. \\
\hline 0.087 & 10 & 0.6 & N.C. & N.C. & N.C. \\
\hline 0.087 & 10 & 0.8 & 7.5 & -9.5 & 5.7 \\
\hline 0.087 & 10 & 1.0 & 6.8 & -10.2 & 1.8 \\
\hline 0.087 & 10 & 1.2 & 6.5 & -10.4 & 0.3 \\
\hline 0.087 & 10 & 1.4 & 6.3 & -10.6 & 5.2 \\
\hline 0.087 & 10 & 1.6 & 6.2 & -10.7 & 14.6 \\
\hline 0.087 & 10 & 1.8 & 6.1 & -10.7 & 26.7 \\
\hline 0.087 & 10 & 2.0 & 6.1 & -11.8 & 40.2 \\
\hline
\end{tabular}

${ }^{a}$ Ionic strength in mol/liter.

${ }^{b}$ Site density in sites per $\mathrm{nm}^{2}$.

${ }^{c}$ Inner-layer capacitance in $\mathrm{F} / \mathrm{m}^{2}$.

${ }^{d}$ No convergence in numeric scheme. 
TABLE IVa

Representative Sensitivity of TLM to Variations in Total Site Density and Ionic Strength Using $\alpha$-FeOOH Titration Data $^{a}$

\begin{tabular}{lrrrrr}
\hline I.S. $^{b}$ & $N_{\mathrm{s}}{ }^{c}$ & $C_{1}^{d}$ & $\log K_{\text {An }}$ & Log $K_{\text {Cat }}$ & $F$ \\
\hline CIS & 1 & 0.8 & 10.50 & -6.16 & 24.8 \\
CIS & 10 & 0.8 & 9.20 & -7.86 & 17.9 \\
CIS & 100 & 0.8 & 8.18 & -8.88 & 18.4 \\
0.005 & 1 & 0.8 & 10.48 & -6.80 & 32.10 \\
0.005 & 10 & 0.8 & 9.28 & -8.01 & 14.60 \\
0.005 & 100 & 0.8 & 8.27 & -9.11 & 13.60 \\
0.028 & 1 & 0.8 & 10.46 & -6.62 & 18.60 \\
0.028 & 10 & 0.8 & 8.96 & -8.15 & 10.80 \\
0.028 & 100 & 0.8 & 7.93 & -9.18 & 10.30 \\
0.087 & 1 & 0.8 & N.C. & N.C. & N.C. \\
0.087 & 10 & 0.8 & 9.01 & -7.94 & 5.76 \\
0.087 & 100 & 0.8 & 7.94 & -9.02 & 5.70 \\
\hline
\end{tabular}

${ }^{a} \log K^{+} 8.60, \log K^{-}-8.60$, outer-layer capacitance $0.2 \mathrm{~F} / \mathrm{m}^{2}$.

${ }^{b}$ Ionic strength in mol/liter.

${ }^{c}$ Site density in sites per $\mathrm{nm}^{2}$.

${ }^{d}$ Inner-layer capacitance in $\mathrm{F} / \mathrm{m}^{2}$.

${ }^{e}$ Combined ionic-strength case. Constants calculated for best fit over 3 ionic strengths of $0.005,0.028$, and $0.087 M$.

${ }^{f}$ No convergence in numeric scheme.

Whether the best-fit values are determined from single or combined ionic-strength data sets appeared to have little influence on the best-fit values for $\log K_{\text {An }}, \log K_{\text {Cat }}$ (Table IVa).

In the case of the TLM, there appears to be a best value of $C_{1}$ for fitting the $\alpha-\mathrm{Al}_{2} \mathrm{O}_{3}$ and $\alpha$-FeOOH titration data sets (e.g., $C_{1}=0.8 \mathrm{~F} /$ $\mathrm{m}^{2}$ is best for $\alpha-\mathrm{FeOOH}$ as shown in Table V). In contrast, all $C_{1}$ values from 0.6 to 1.2 $\mathrm{F} / \mathrm{m}^{2}$ for the $\mathrm{TiO}_{2}$ titration data set resulted in excellent fits, $F$ values less than 50 . In general, as $C_{1}$ increased, the values for the electrolyte surface constants decreased for a given value of $\Delta \mathrm{p} K_{\mathrm{a}}$ and $N_{\mathrm{s}}$. As explained above for the CCM, as the value of $C_{1}$ increases, the values of the surface protolysis constants have to decrease to compensate for the effective increase in acidity (proton release) which results from enhanced charge screening. The decrease in the electrolyte binding constants with in- creasing $C_{1}$ was greatest for the $\alpha-\mathrm{FeOOH}$ titration data sets, changing about $1.5 \log$ units in going from $C_{1}=0.6$ to $C_{1}=1.2 \mathrm{~F} / \mathrm{m}^{2}$; for

\section{TABLE IVb}

Representative Sensitivity of TLM to Variations in Inner-Layer Capacitance and Ionic Strength Using $\alpha$-FeOOH Titration Data ${ }^{a}$

\begin{tabular}{|c|c|c|c|c|c|}
\hline I.S. ${ }^{b}$ & $N_{\mathrm{s}}^{c}$ & $C_{\mathrm{l}}^{d}$ & $\log K_{\text {An }}$ & $\log K_{\text {Cat }}$ & $F$ \\
\hline CIS $^{e}$ & 10 & 0.6 & 10.09 & -7.14 & 53.4 \\
\hline CIS & 10 & 0.8 & 9.20 & -7.86 & 17.9 \\
\hline CIS & 10 & 1.0 & 8.75 & -8.27 & 43.0 \\
\hline CIS & 10 & 1.2 & 8.48 & -8.55 & 76.2 \\
\hline CIS & 10 & 1.4 & 8.29 & -8.73 & 108.6 \\
\hline CIS & 10 & 1.6 & 8.16 & -8.85 & 139.2 \\
\hline CIS & 10 & 1.8 & 8.06 & -9.01 & 167.9 \\
\hline CIS & 10 & 2.0 & 7.98 & -9.06 & 193.1 \\
\hline 0.005 & 10 & 0.6 & 9.97 & -7.25 & 37.20 \\
\hline 0.005 & 10 & 0.8 & 9.28 & -8.01 & 14.60 \\
\hline 0.005 & 10 & 1.0 & 9.01 & -8.24 & 3.08 \\
\hline 0.005 & 10 & 1.2 & 8.83 & -8.37 & 5.03 \\
\hline 0.005 & 10 & 1.4 & 8.70 & -8.46 & 14.3 \\
\hline 0.005 & 10 & 1.6 & 8.60 & -8.52 & 26.3 \\
\hline 0.005 & 10 & 1.8 & 8.52 & -8.57 & 39.5 \\
\hline 0.005 & 10 & 2.0 & 8.45 & -8.61 & 52.8 \\
\hline 0.028 & 10 & 0.6 & N.C. ${ }^{f}$ & N.C. & N.C. \\
\hline 0.028 & 10 & 0.8 & 8.96 & -8.15 & 10.80 \\
\hline 0.028 & 10 & 1.0 & 8.56 & -8.54 & 2.16 \\
\hline 0.028 & 10 & 1.2 & 8.34 & -8.73 & 1.17 \\
\hline 0.028 & 10 & 1.4 & 8.20 & -8.84 & 6.66 \\
\hline 0.028 & 10 & 1.6 & 8.08 & -8.92 & 15.5 \\
\hline 0.028 & 10 & 1.8 & 7.99 & -8.98 & 25.9 \\
\hline 0.028 & 10 & 2.0 & 7.92 & -9.03 & 37.0 \\
\hline 0.087 & 10 & 0.6 & N.C. & N.C. & N.C. \\
\hline 0.087 & 10 & 0.8 & 9.01 & -7.94 & 5.76 \\
\hline 0.087 & 10 & 1.0 & 8.28 & -8.67 & 2.00 \\
\hline 0.087 & 10 & 1.2 & 8.00 & -8.92 & 10.60 \\
\hline 0.087 & 10 & 1.4 & 7.82 & -9.06 & 3.48 \\
\hline 0.087 & 10 & 1.6 & 7.69 & -9.15 & 10.38 \\
\hline 0.087 & 10 & 1.8 & 7.59 & -9.22 & 19.19 \\
\hline 0.087 & 10 & 2.0 & 7.51 & -9.28 & 29.0 \\
\hline
\end{tabular}

${ }^{a} \log K^{+} 8.60, \log K^{-}-8.60$, outer-layer capacitance $0.2 \mathrm{~F} / \mathrm{m}^{2}$.

${ }^{b}$ Ionic strength in mol/liter.

'Site density in sites per $\mathrm{nm}^{2}$.

${ }^{d}$ Inner-layer capacitance in $\mathrm{F} / \mathrm{m}^{2}$.

${ }^{e}$ Combined ionic-strength case. Constants calculated for best fit over 3 ionic strengths of $0.005,0.028$, and $0.087 \mathrm{M}$.

${ }^{f}$ No convergence in numeric scheme. Note: no convergence was achieved for any conditions above when $C_{1}$ was less than or equal to $0.4 \mathrm{~F} / \mathrm{m}^{2}$. 


\section{TABLE V}

Representative Sensitivity of TLM to Variations in Inner-Layer Capacitance, $\Delta \mathrm{p} K_{\mathrm{a}},{ }^{a}$ and Site Density Using $\alpha$ FeOOH Titration Data ${ }^{b}$

\begin{tabular}{|c|c|c|c|c|c|}
\hline$C_{\mathrm{i}}^{c}$ & $N_{\mathrm{s}}^{d}$ & $\Delta p K_{\mathrm{a}}$ & $\log K_{\mathrm{An}}$ & $\log K_{\text {Cat }}$ & $F$ \\
\hline 0.8 & 1 & 0 & 10.50 & -6.16 & 24.8 \\
\hline 0.8 & 1 & 2 & 10.11 & -7.00 & 25.4 \\
\hline 0.8 & 1 & 4 & 10.07 & -7.05 & 25.9 \\
\hline 0.8 & 1 & 6 & 10.08 & -7.04 & 25.9 \\
\hline 0.8 & 1 & 8 & 10.08 & -7.04 & 25.9 \\
\hline 0.6 & 10 & 0 & 10.06 & -7.14 & 53.4 \\
\hline 0.6 & 10 & 2 & 9.70 & -7.53 & 53.3 \\
\hline 0.6 & 10 & 4 & 9.63 & -7.60 & 53.3 \\
\hline 0.6 & 10 & 6 & 9.62 & -7.61 & 53.3 \\
\hline 0.6 & 10 & 8 & 9.62 & -7.61 & 53.3 \\
\hline 0.8 & 10 & 0 & 9.20 & -7.86 & 17.9 \\
\hline 0.8 & 10 & 2 & 8.80 & -8.26 & 17.9 \\
\hline 0.8 & 10 & 4 & 8.74 & -8.33 & 17.9 \\
\hline 0.8 & 10 & 6 & 8.74 & -8.32 & 18.0 \\
\hline 0.8 & 10 & 8 & 8.75 & -8.31 & 18.3 \\
\hline 1.0 & 10 & 0 & 8.75 & -8.27 & 43.0 \\
\hline 1.0 & 10 & 2 & 8.36 & -8.67 & 43.0 \\
\hline 1.0 & 10 & 4 & 8.29 & -8.74 & 43.3 \\
\hline 1.0 & 10 & 6 & 8.30 & -8.72 & 44.9 \\
\hline 1.0 & 10 & 8 & 8.33 & -8.70 & 47.3 \\
\hline 1.2 & 10 & 0 & 8.48 & -8.55 & 76.2 \\
\hline 1.2 & 10 & 2 & 8.08 & -8.95 & 76.3 \\
\hline 1.2 & 10 & 4 & 8.02 & -9.02 & 77.1 \\
\hline 1.2 & 10 & 6 & 8.04 & -9.00 & 81.8 \\
\hline 1.2 & 10 & 8 & 8.07 & -8.97 & 88.8 \\
\hline 0.8 & 100 & 0 & 8.18 & -8.88 & 18.4 \\
\hline 0.8 & 100 & 2 & 7.78 & -9.28 & 18.4 \\
\hline 0.8 & 100 & 4 & 7.71 & -9.35 & 18.4 \\
\hline 0.8 & 100 & 6 & 7.70 & -9.35 & 18.4 \\
\hline 0.8 & 100 & 8 & 7.71 & -9.34 & 18.6 \\
\hline
\end{tabular}

${ }^{a}\left(-\left[\left(\log K^{-}\right)+\left(\log K^{+}\right)\right]\right)$.

${ }^{b}$ Outer-layer capacitance $0.2 \mathrm{~F} / \mathrm{m}^{2}$ and all ionic strength case used.

${ }^{c}$ Inner-layer capacitance in $\mathrm{F} / \mathrm{m}^{2}$.

${ }^{d}$ Site density in sites per $\mathbf{n m}^{2}$.

the $\alpha-\mathrm{Al}_{2} \mathrm{O}_{3}$ and $\mathrm{TiO}_{2}$ titration data sets, for the same range of values of $C_{1}$, the electrolyte binding constants changed about 1.1 and $0.6 \log$ units, respectively. The greater relative changes for $\alpha$-FeOOH and $\alpha-\mathrm{Al}_{2} \mathrm{O}_{3}$ compared to $\mathrm{TiO}_{2}$ may be due to the smaller effect of ionic strength on the titration behavior of the former compared to the later.
The effects of changes in $\Delta \mathrm{p} K_{\mathrm{a}}$ on the bestfit values of $\log K_{\text {An }}$ and $\log K_{\text {Cat }}$ are shown in Table $\mathrm{V}$. When $\Delta \mathrm{p} K_{\mathrm{a}}$ increases from 0 to 3 , the best-fit values of $\log K_{\text {An }}$ and $\log K_{\text {Cat }}$ decrease. For $\Delta \mathrm{p} K_{\mathrm{a}}$ values larger than 3 , further increases in $\Delta \mathrm{p} K_{\mathrm{a}}$ have little or no effect on the values of the best-fit electrolyte binding constants. These trends are a result of the rel-
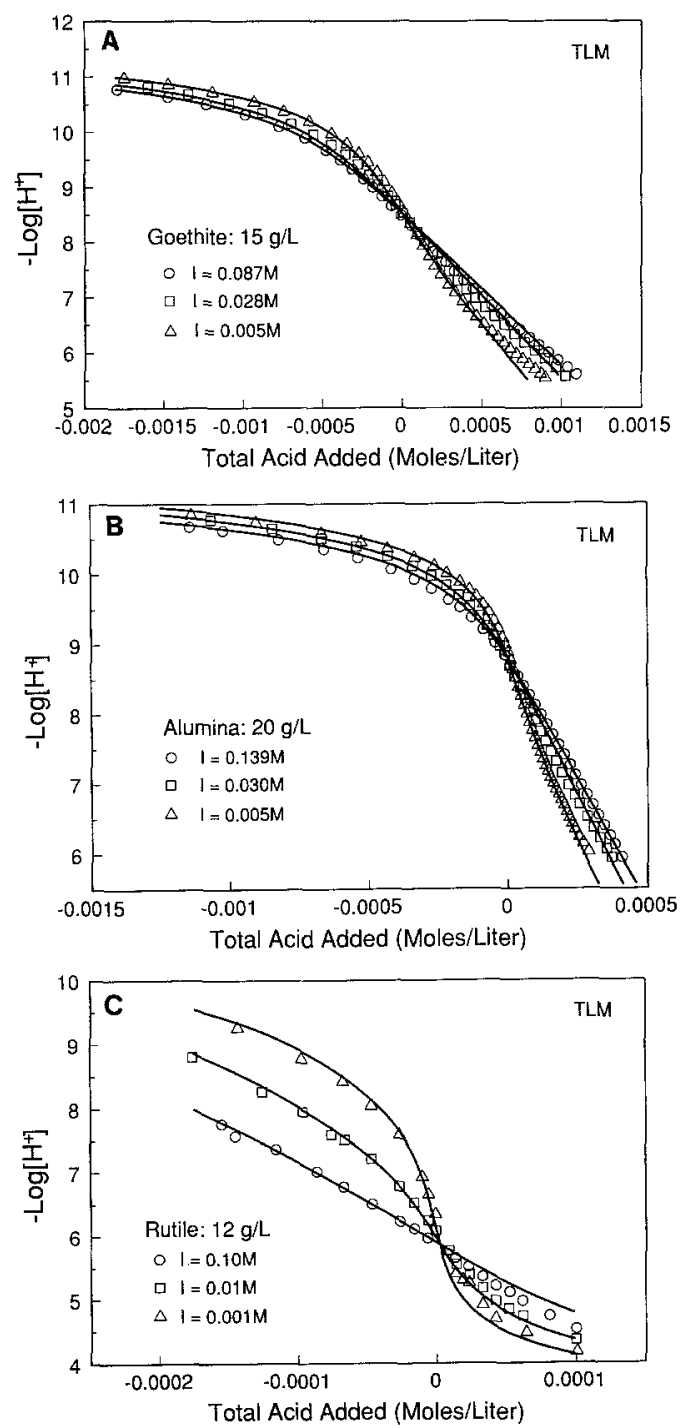

FIG. 4. Triple-layer model fits of titration data for suspensions of (A) $\alpha$-FeOOH, (B) $\alpha-\mathrm{Al}_{2} \mathrm{O}_{3}$, and (C) $\mathrm{TiO}_{2}$ at various $\mathrm{NaNO}_{3}$ concentrations. Values for the parameters used in the model simulations are given in Table VI. 
ative contribution of the surface acidity and electrolyte binding constants on the net proton adsorption or desorption behavior. When $\Delta \mathrm{p} K_{\mathrm{a}}=0,\left[\mathrm{SOH}_{2}^{+}\right]=\left[\mathrm{SO}^{-}\right]$and therefore only the concentration of the species $\mathrm{SOH}_{2}^{+}-\mathrm{An}^{-}, \mathrm{SO}^{-}-\mathrm{Cat}^{+}, \mathrm{H}^{+}$and $\mathrm{OH}^{-}$contribute to the titration behavior since $\left[\mathrm{SOH}_{2}^{+}\right]$and $\left[\mathrm{SO}^{-}\right]$cancel each other out in Eq. [8]. As a result, the relative proton release described by Eq. [8] is dominated between $\mathrm{pH}$ 4 and 10 by the electrolyte binding reactions. As $\Delta \mathrm{p} K_{\mathrm{a}}$ increases, the $\left[\mathrm{SOH}_{2}^{+}\right]$and $\left[\mathrm{SO}^{-}\right]$ begin to differ, and since they do not identically cancel out in Eq. [8], they begin to contribute to the net number of protons consumed or released as a function of $\mathrm{pH}$. In order to compensate, the electrolyte binding constants decrease. When $\Delta \mathrm{p} K_{\mathrm{a}}$ increases beyond 3, $\left[\mathrm{SOH}_{2}^{+}-\mathrm{An}^{-}\right]$and $\left[\mathrm{SO}^{-}-\mathrm{Cat}^{+}\right]$again dominate the net proton release and consumption at $\mathrm{pH}$ values below and above the PSZE, respectively, because of the relatively lower concentrations of $\left[\mathrm{SOH}_{2}^{+}\right]$and $\left[\mathrm{SO}^{-}\right]$at high values of $\Delta \mathrm{p} K_{\mathrm{a}}$. This results in no change in the best-fit values of $\log K_{\text {An }}$ and $\log K_{\text {Cat }}$ when $\Delta K_{\mathrm{a}}$ increases beyond 3 .

In view of the wide range of parameter values that fit the titration data reasonably well (e.g., a range in $N_{\mathrm{s}}$ of two orders of magnitude, $C_{1}$ ranging from 0.6 to $2.0 \mathrm{~F} / \mathrm{m}^{2}$, and $\Delta \mathrm{p} K_{\mathrm{a}}$ ranging from 0 to 8 ), a suitable strategy needs to be developed to arrive at a "unique" set of SCM parameter values. Assuming that an accurate estimate of $N_{\mathrm{s}}$ can be made and that a best value of $C_{1}$ can be determined from the sensitivity analysis or that a suitable value will be chosen (e.g., $0.8 \mathrm{~F} / \mathrm{m}^{2}$ ), then two of the three degrees of freedom are eliminated. What remains is to develop a strategy for choosing a unique value for $\Delta \mathrm{p} K_{\mathrm{a}}$. Koopal et al. (8) suggest from a chemical point of view that small $\Delta \mathrm{p} K_{\mathrm{a}}$ values (less than one) are preferred. However, from a modeling perspective, based on a best-fit criterion described here, there appears to be no a priori justification for picking one set of $\Delta \mathrm{p} K_{\mathrm{a}}$ values from another. In absence of any compelling reason to support any one $\Delta \mathrm{p} K_{\mathrm{a}}$ value, we suggest choosing
$\Delta \mathrm{p} K_{\mathrm{a}}$ to be 4 . Choosing a value of 4 ensures that the best-fit values of the surface electrolyte binding constants will be insensitive to slight changes in $\Delta \mathrm{p} K_{\mathrm{a}}$. However, several FITEQL runs should be made with $\Delta \mathrm{p} K_{\mathrm{a}}$ chosen as the only variable between runs. $\Delta \mathrm{p} K_{\mathrm{a}}$ steps of two are suggested in the range from 0 to 8 (or a maximum spread not greater than will bracket the entire $\mathrm{pH}$ range of the data set). If a significant improvement in fit is observed with any of these $\Delta \mathrm{p} K_{\mathrm{a}}$ values compared to the $\Delta \mathrm{p} K_{\mathrm{a}}$ value of 4 , then this value should be adopted.

Table VI gives the suggested values for the DLM, CCM, and TLM parameters for $\alpha$ $\mathrm{FeOOH}, \alpha-\mathrm{Al}_{2} \mathrm{O}_{3}$, and $\mathrm{TiO}_{2}$ based on the approaches described above for determining a unique set of parameter values for each of these SCMs.

Effects of quality and extent of titration data on the sensitivity analysis. An additional objective of this study was to evaluate the effects that the quality and extent of the titration data have on the determination of a "unique" set of SCM parameter values using FITEQL. Two types of analyses were performed. In the first, subsets of data points were taken from the titration data sets to see if the density or the $\mathrm{pH}$ range of the data points would have a dramatic effect on FITEQL best-fit values. The results using the DLM, CCM, and TLM and the $\alpha$ $\mathrm{Al}_{2} \mathrm{O}_{3}$ titration data are shown in Table VII. In general, the number or density of points have little effect on the best-fit values. Although not shown, the fewer the number of data points used, the higher the resulting standard deviations of the best-fit values. This is expected since the standard deviation, by definition, is inversely proportional to the number of data points. The $\mathrm{pH}$ range of data points also seemed to have only a small effect which, in the case of the $\alpha-\mathrm{Al}_{2} \mathrm{O}_{3}$, caused only a $0.3 \log$ unit change in the best-fit values when the $\mathrm{pH}$ range was reduced from 2 to $1 \mathrm{pH}$ units.

In the second type of analysis, the acid or base leg only (the portion of the titration curve below or above the $\mathrm{pH}_{\mathrm{PZSE}}$, respectively) was 
TABLE VI

Suggested "Standard" Parameter Values for DLM, CCM, and TLM

\begin{tabular}{|c|c|c|c|c|c|c|c|c|}
\hline \multicolumn{9}{|c|}{$\mathrm{DLM}^{a}$ parameter values } \\
\hline Solid $^{b}$ & \multicolumn{3}{|c|}{$N_{s}^{c}$} & \multicolumn{2}{|c|}{$\mathrm{pH}_{\mathrm{PZSE}}$} & \multicolumn{2}{|c|}{$\log K^{+}$} & $\log K^{-}$ \\
\hline$\alpha-\mathrm{FeOOH}$ & \multicolumn{3}{|c|}{10} & \multicolumn{2}{|c|}{8.60} & \multicolumn{2}{|c|}{7.10} & -10.24 \\
\hline$\alpha-\mathrm{Al}_{2} \mathrm{O}_{3}$ & & 10 & & \multirow{2}{*}{\multicolumn{2}{|c|}{$\begin{array}{l}8.90 \\
5.90\end{array}$}} & \multicolumn{2}{|c|}{7.29} & -11.13 \\
\hline $\mathrm{TiO}_{2}$ & & 10 & & & & & & -7.94 \\
\hline \multicolumn{9}{|c|}{$\mathrm{CCM}^{d}$ parameter values } \\
\hline Solids $^{b}$ & I.S. & & $N_{s}^{e}$ & & & $\mathrm{pH}_{\mathrm{PZSE}}$ & $\log K^{+}$ & $\log K^{-}$ \\
\hline \multirow[t]{3}{*}{$\alpha$-FeOOH } & 0.005 & & 10 & & & 8.60 & 6.2 & -11.0 \\
\hline & 0.028 & & 10 & & & 8.60 & 6.6 & -10.6 \\
\hline & 0.087 & & 10 & & & 8.60 & 6.8 & -10.2 \\
\hline \multirow[t]{3}{*}{$\alpha-\mathrm{Al}_{2} \mathrm{O}_{3}$} & 0.005 & & 10 & & & 8.90 & 6.4 & -11.8 \\
\hline & 0.030 & & 10 & & & 8.90 & 6.8 & -10.8 \\
\hline & 0.139 & & 10 & & & 8.90 & 7.2 & -10.3 \\
\hline \multirow[t]{3}{*}{$\mathrm{TiO}_{2}$} & 0.001 & & 10 & & & 5.90 & 2.8 & -9.2 \\
\hline & 0.010 & & 10 & & & 5.90 & 3.1 & -8.8 \\
\hline & 0.100 & & 10 & & & 5.90 & 3.5 & -8.1 \\
\hline \multicolumn{9}{|c|}{$\operatorname{TLM}^{f}$ parameter values } \\
\hline Solid ${ }^{b}$ & $N_{s}^{c}$ & $C_{1}^{e}$ & & $C_{2}^{*}$ & $\Delta \mathrm{p} K_{\mathrm{a}}$ & $\mathrm{pH}_{\mathrm{PZSE}}$ & $\log K_{\mathrm{CAt}}$ & $\log K_{\mathrm{An}}$ \\
\hline$\alpha-\mathrm{FeOOH}$ & 10 & 0.8 & & 0.2 & 4.0 & 8.60 & -8.33 & 8.74 \\
\hline$\alpha-\mathrm{Al}_{2} \mathrm{O}_{3}$ & 10 & 0.8 & & 0.2 & 4.0 & 8.90 & -8.80 & 8.89 \\
\hline $\mathrm{TiO}_{2}$ & 10 & 0.8 & & 0.2 & 4.0 & 5.90 & -6.88 & 4.84 \\
\hline
\end{tabular}

${ }^{a}$ DLM parameter values used for SCM simulations in Fig. 2.

${ }^{b}$ Solid concentrations $\left(\mathrm{S}_{\mathrm{A}}\right) ; \alpha$-FeOOH, $15 \mathrm{~g} / \mathrm{liter}\left(52 \mathrm{~m}^{2} / \mathrm{g}\right) ; \alpha-\mathrm{Al}_{2} \mathrm{O}_{3} 20 \mathrm{~g} / \mathrm{liter}\left(12 \mathrm{~m}^{2} / \mathrm{g}\right) ; \mathrm{TiO}_{2}, 12 \mathrm{~g} / \mathrm{liter}\left(20 \mathrm{~m}^{2} / \mathrm{g}\right)$.

${ }^{c}$ Site density in sites per $\mathrm{nm}^{2}$.

${ }^{d} \mathrm{CCM}$ parameter values used for SCM simulations in Fig. 3.

e Capacitance in $\mathrm{F} / \mathrm{m}^{2}$.

${ }^{f}$ TLM parameter values used for SCM simulations in Fig. 4.

fit using FITEQL with the TLM version. Under these conditions the values of the best-fit constants differed very little from those generated using the complete titration data sets (Table VIII). This implies that SCM constants can be generated with less than complete sets of titration data on either side of the $\mathrm{pH}_{\text {PZSE }}$. This may be important for complex natural materials since it may be difficult to obtain titration data over a wide range of $\mathrm{pH}$ values due to enhanced mineral solubility that might occur at $\mathrm{pH}$ extremes or when the $\mathrm{pH}_{\mathrm{PZSE}}$ is at very low or high $\mathrm{pH}$ values.
Effect of absolute and relative error on sensitivity analysis. In order to evaluate the sensitivity of the models to experimental error estimates of the titration data, the changes in the FITEQL best-fit values and their standard deviations as a function of the values assumed for the absolute and relative errors were evaluated (Table IX). Comparisons are made relative to values that are considered typical for titration data (e. g., 0.01 relative error and 2.0 $\times 10^{-8} \mathrm{M}$ absolute error in total acid added, and 0.05 relative error and 0.0 absolute error in hydrogen ion concentration). As can be 


\section{TABLE VII}

Sensitivity of TLM to Variations in Density and Distribution of Data Points Using $\alpha-\mathrm{Al}_{2} \mathrm{O}_{3}$ Titration Data $^{a}$

\begin{tabular}{lcccc}
\hline \multicolumn{1}{c}{ Data set } & $\log K_{\text {An }}$ & Log $K_{\text {Cat }}$ & $F$ & Avg. change \\
\hline Original & 8.96 & -8.74 & 10.3 & $0 \%$ \\
$50 \%^{b}$ & 8.96 & -8.73 & 10.4 & $<1 \%$ \\
$25 \%^{c}$ & 8.97 & -8.72 & 11.3 & $<1 \%$ \\
$12 \%^{d}$ & 8.99 & -8.70 & 11.7 & $<1 \%$ \\
$8 \%^{e}$ & 9.09 & -8.58 & 5.80 & $1.6 \%$ \\
$5 \%^{f}$ & 9.15 & -8.50 & 4.59 & $2.4 \%$ \\
$2.0 \mathrm{pH}^{g}$ & 8.85 & -8.90 & 15.0 & $1.7 \%$ \\
$1.0 \mathrm{pH}^{h}$ & 8.45 & -9.20 & 18.8 & $5.5 \%$ \\
\hline
\end{tabular}

${ }^{a}$ Original data set of 114 points over 3 ionic strengths $(0.005,0.030$, and $0.139 \mathrm{M}), \mathrm{pH}$ range of 5.9 to $10.8, \mathrm{C}_{1}$ $0.8 \mathrm{~F} / \mathrm{m}^{2}, C_{2} 0.2 \mathrm{~F} / \mathrm{m}^{2}, N_{\mathrm{s}} 10$ sites $/ \mathrm{nm}^{2}$, and $\Delta \mathrm{p} K_{\mathrm{a}} 2$.

${ }^{b}$ Every second data point deleted ( 57 total data points).

${ }^{c}$ Every fourth data point included (29 total data points).

${ }^{d}$ Every eighth data point included ( 14 total data points).

${ }^{e}$ Extreme points and midpoint of each ionic strength included ( 9 total data points).

${ }^{f}$ Extreme and central point for each ionic strength included ( 6 total data points).

${ }^{g}$ Only data points between $\mathrm{pH}$ of 7.9 and 9.9 included.

${ }^{h}$ Only data points between $\mathrm{pH}$ of 8.4 and 9.4 included.

seen in Table IX for $\alpha$-FeOOH titration data, changes in the relative and absolute error in total acid added over a relatively wide range ( 0.0 to 0.5 and $2.0 \times 10^{-6}$ to $0.0 \mathrm{M}$, respectively) have little effect on the best-fit $\log K$ values. For example, in the case of the TLM, if the assumed absolute error in the $\mathrm{pH}$ measurements is 0.25 units ( which gives a relative error in hydrogen ion concentration of 0.5 or $50 \%$ ) the values of the best-fit constants change by a maximum of $0.1 \log$ unit. Since we usually can measure $\mathrm{pH}$ better than \pm 0.25 , the assumed error will usually not greatly influence the best-fit values. The same can be said for the error associated with the preparation of the titrant and error in titrant delivery. Typically, we can prepare standards and titrate accurately enough that best-fit value should not depend too strongly on the error input into FITEQL, assuming the experimental error falls within the reasonable range as discussed here. All of the SCMs showed similar sensitivity to changes in the quality and extent of titration data.

Model Titration Data Sets. For comparison with sensitivity analysis of the experimental titration data, "model-generated titration data sets" using known values for all of model constants were obtained, and these model-generated titration data sets were analyzed using the sensitivity analysis protocol described above. In the case of the DLM or the CCM, if the original value of $N_{\mathrm{s}}$ or $N_{\mathrm{s}}$ and $C_{1}$ were specified, respectively, then the resulting FITEQL best-fit values of the surface protolysis constants were the same, within experimental error, as those originally used to generate model titration data. However, in the case of the TLM, even when inputting the original values for $C_{1}, C_{2}$, and $N_{\mathrm{s}}$, the original set of surface constants would not be generated from FITEQL unless the $\Delta \mathrm{p} K_{\mathrm{a}}$ that was originally used was also specified. This underscores the point that, when using the TLM, an infinite set of surface constants can be found to model the titration data equally well. This result is consistent with those of the TLM sensitivity analysis presented for the experimental titration data sets, and confirms that the TLM model is not constrained enough to represent the titration behavior uniquely with one set of surface equilibrium constants.

In comparing the relative merits of each model to fit the different titration data sets, the above analysis shows that, in the case of the $\alpha-\mathrm{FeOOH}$ and $\alpha-\mathrm{Al}_{2} \mathrm{O}_{3}$ titration data sets, the SCMs with more fitting parameters fit the titration data better. This is in contrast to the study of Westall and Hohl (7) who have previously demonstrated for the $\mathrm{TiO}_{2}$ titration data that all of the SCMs were able to simulate titration data equally well. We also found that the $\mathrm{TiO}_{2}$ titration data could be simulated equally well by the DLM, CCM, and TLM. An explanation for why $\mathrm{TiO}_{2}$ titration data is fit equally well by all SCMs while $\alpha-\mathrm{FeOOH}$ and $\alpha-\mathrm{Al}_{2} \mathrm{O}_{3}$ are fit much better by the TLM compared to the DLM or CCM awaits evaluation of more titration data sets. 
TABLE VIII

Response of Models to Only Acid or Base Leg Data ${ }^{a}$

\begin{tabular}{|c|c|c|c|c|c|c|c|}
\hline Model & Solid & I.S. & $\log K_{\mathrm{An}}$ & $\log K_{\text {Cat }}$ & Comp. $\log ^{b}$ & $F$ & Comp. $F^{b}$ \\
\hline TLM & $\alpha-\mathrm{FeOOH}$ & CIS $^{c}$ & 9.18 & -7.86 & 9.20 & 22.2 & 17.9 \\
\hline TLM & $\alpha-\mathrm{FeOOH}$ & CIS & $\underline{9.20}$ & -8.01 & -7.86 & 5.12 & 17.9 \\
\hline TLM & $\alpha-\mathrm{FeOOH}$ & $0.028 M$ & $\overline{8.95}$ & -8.15 & 8.96 & 1.62 & 10.8 \\
\hline TLM & $\alpha-\mathrm{FeOOH}$ & $0.028 M$ & $\underline{8.96}$ & $-8 . \overline{23}$ & -8.15 & 0.58 & 10.8 \\
\hline TLM & $\alpha-\mathrm{Al}_{2} \mathrm{O}_{3}$ & CIS & 9.36 & -8.34 & 9.36 & 8.51 & 10.3 \\
\hline TLM & $\alpha-\mathrm{Al}_{2} \mathrm{O}_{3}$ & CIS & $\underline{9.36}$ & -8.43 & -8.34 & 12.0 & 10.3 \\
\hline TLM & $\alpha-\mathrm{Al}_{2} \mathrm{O}_{3}$ & $0.030 M$ & $\overline{9.19}$ & -8.42 & 9.20 & 7.14 & 5.07 \\
\hline TLM & $\alpha-\mathrm{Al}_{2} \mathrm{O}_{3}$ & $0.030 \mathrm{M}$ & $\underline{9.20}$ & -8.52 & -8.42 & 0.99 & 5.07 \\
\hline TLM & $\mathrm{TiO}_{2}$ & CIS & 5.26 & -6.40 & 5.28 & 64.5 & 33.9 \\
\hline TLM & $\mathrm{TiO}_{2}$ & CIS & 5.28 & $\overline{-6.41}$ & -6.40 & 8.02 & 33.9 \\
\hline TLM & $\mathrm{TiO}_{2}$ & $0.010 M$ & $\overline{5.51}$ & -6.41 & 5.53 & 0.56 & 0.64 \\
\hline \multirow[t]{2}{*}{ TLM } & $\mathrm{TiO}_{2}$ & $0.010 \mathrm{M}$ & $\underline{5.53}$ & $\overline{-6.41}$ & -6.41 & 0.68 & 0.64 \\
\hline & & & $\log K^{+}$ & $\log K^{-}$ & & & \\
\hline DLM & $\alpha-\mathrm{FeOOH}$ & CIS & 7.17 & -10.24 & 7.10 & 234 & 201 \\
\hline DLM & $\alpha-\mathrm{FeOOH}$ & CIS & $\underline{7.10}$ & -9.71 & -10.24 & 31.0 & 201 \\
\hline DLM & $\alpha-\mathrm{FeOOH}$ & $0.020 \mathrm{M}$ & $\overline{7.20}$ & -10.00 & 7.14 & 56.1 & 58.4 \\
\hline DLM & $\alpha$-FeOOH & $0.020 \mathrm{M}$ & $\underline{7.14}$ & -9.64 & -10.00 & 9.26 & 58.4 \\
\hline DLM & $\alpha-\mathrm{Al}_{2} \mathrm{O}_{3}$ & CIS & 7.33 & -11.13 & 7.29 & 203 & 162 \\
\hline DLM & $\alpha-\mathrm{Al}_{2} \mathrm{O}_{3}$ & CIS & 7.29 & -10.21 & -11.13 & 8.01 & 162 \\
\hline DLM & $\alpha-\mathrm{Al}_{2} \mathrm{O}_{3}$ & $0.030 \mathrm{M}$ & 7.36 & -10.59 & 7.33 & 40.1 & 39.2 \\
\hline DLM & $\alpha-\mathrm{Al}_{2} \mathrm{O}_{3}$ & $0.030 M$ & $\underline{7.33}$ & -10.06 & -10.59 & 4.08 & 39.2 \\
\hline DLM & $\mathrm{TiO}_{2}$ & CIS & 3.83 & -7.94 & 3.86 & 46.6 & 29.7 \\
\hline DLM & $\mathrm{TiO}_{2}$ & CIS & $\underline{3.86}$ & $\overline{-7.92}$ & -7.94 & 15.0 & 29.7 \\
\hline DLM & $\mathrm{TiO}_{2}$ & $0.010 \mathrm{M}$ & 4.04 & $=7.87$ & 4.05 & 0.33 & 0.80 \\
\hline DLM & $\mathrm{TiO}_{2}$ & $0.010 M$ & 4.05 & -7.87 & -7.87 & 1.15 & 0.80 \\
\hline $\mathrm{CCM}$ & $\alpha-\mathrm{FeOOH}$ & $0.028 M$ & 6.56 & -10.55 & 6.56 & 2.24 & 1.65 \\
\hline $\mathrm{CCM}$ & $\alpha-\mathrm{FeOOH}$ & $0.028 M$ & $\underline{6.56}$ & -10.56 & -10.56 & 0.83 & 1.65 \\
\hline $\mathrm{CCM}$ & $\alpha-\mathrm{Al}_{2} \mathrm{O}_{3}$ & $0.030 M$ & 6.83 & -10.82 & 6.83 & 0.21 & 0.50 \\
\hline $\mathrm{CCM}$ & $\alpha-\mathrm{Al}_{2} \mathrm{O}_{3}$ & $0.030 M$ & $\underline{6.83}$ & -10.83 & -10.82 & 0.85 & 0.50 \\
\hline $\mathrm{CCM}$ & $\mathrm{TiO}_{2}$ & $0.010 M$ & 3.14 & -8.83 & 3.13 & 1.20 & 1.44 \\
\hline CCM & $\mathrm{TiO}_{2}$ & $0.010 \mathrm{M}$ & $\underline{3.13}$ & -8.82 & -8.83 & 1.59 & 1.44 \\
\hline
\end{tabular}

${ }^{a}$ For all models: site density 10 sites $/ \mathrm{nm}^{2} ; C_{2} 0.2 \mathrm{~F} / \mathrm{m}^{2}: \Delta \mathrm{p} K_{\mathrm{a}} 0 ;$ for TLM and DLM: $C_{1} 0.8 \mathrm{~F} / \mathrm{m}^{2} ;$ for CCM; $C_{1} 1.0$ $\mathrm{F} / \mathrm{m}^{2}$.

${ }^{b} \log K_{\mathrm{An}}, \log K_{\mathrm{Cat}}$, or $F$ calculated from full $\mathrm{pH}$ range for comparison with values calculated from acid or base data leg only; i.e., for acid leg $K_{\text {Cat }}$ fixed and $K_{\mathrm{An}}$ calculated for comparison with $K_{\mathrm{An}}$ from full range case. Underlining indicates that the constant is fixed for the single leg case.

${ }^{c}$ Combined ionic strength case.

\section{SUMMARY AND CONCLUSIONS}

The results of the sensitivity analysis can be summarized as follows:
For all models evaluated, increasing the assumed value for the total number of sites resulted in a decrease in the FITEQL best-fit equilibrium $\log K$ values, decreasing on the 
TABLE IX

Response of Models to Variations in Absolute and Relative Error Using $\alpha$-FeOOH Titration Data ${ }^{a}$

\begin{tabular}{|c|c|c|c|c|c|c|c|}
\hline Rel Tot ${ }^{b}$ & Abs $\operatorname{Tot}^{b}$ & Rel Free ${ }^{c}$ & $\left(\log K^{+}\right)^{d}$ & $\left(\sigma K^{+}\right)^{e}$ & $\left(\log K^{+}\right)^{d}$ & $\left(\sigma K^{-}\right)^{e}$ & $F$ \\
\hline \multicolumn{8}{|c|}{ DLM } \\
\hline 0.01 & $2 \mathrm{E}-8$ & 0.05 & 7.10 & 0.013 & -10.24 & 0.033 & 201 \\
\hline 0.10 & $2 E-6$ & 0.05 & 6.98 & 0.052 & -10.10 & 0.104 & 8.07 \\
\hline 0.50 & $2 \mathrm{E}-6$ & 0.05 & 6.98 & 0.166 & -10.08 & 0.417 & 0.46 \\
\hline 0.01 & $2 E-8$ & 0.20 & 7.13 & 0.047 & -10.28 & 0.126 & 16.2 \\
\hline 0.01 & $2 E-8$ & 0.50 & 7.13 & 0.117 & -10.28 & 0.314 & 2.63 \\
\hline 0.001 & $2 \mathrm{E}-10$ & 0.001 & N.C. $f^{f}$ & N.C $f$ & N.C $f$ & N.C. $f^{f}$ & N.C $f^{f}$ \\
\hline 0.0 & 0.0 & 0.0 & 6.81 & 972 & -10.24 & 1813 & $2 \mathrm{E}-8$ \\
\hline \multicolumn{8}{|c|}{$\mathrm{CCM}$} \\
\hline 0.01 & $2 E-8$ & 0.05 & 6.93 & 0.026 & -10.19 & 0.053 & 10.4 \\
\hline 0.10 & $2 \mathrm{E}-6$ & 0.05 & 6.81 & 0.085 & -10.30 & 0.164 & 0.32 \\
\hline 0.50 & $2 E-6$ & 0.05 & 6.79 & 0.243 & -10.32 & 0.665 & 0.015 \\
\hline 0.01 & $2 \mathrm{E}-8$ & 0.20 & 6.99 & 0.086 & -10.12 & 0.202 & 1.10 \\
\hline 0.01 & $2 \mathrm{E}-8$ & 0.50 & 7.00 & 0.212 & -10.11 & 0.504 & 0.18 \\
\hline 0.001 & $2 E-10$ & 0.001 & N.C $f$ & N.C..$^{f}$ & N.C. & N.C $f^{f}$ & N.C. ${ }^{f}$ \\
\hline 0.0 & 0.0 & 0.0 & 6.95 & 2834 & -10.28 & 4091 & $1 E-9$ \\
\hline \multicolumn{8}{|c|}{ TLM } \\
\hline 0.01 & $2 \mathrm{E}-8$ & 0.05 & 8.74 & 0.015 & -8.32 & 0.030 & 17.9 \\
\hline 0.10 & $2 E-6$ & 0.05 & 8.57 & 0.053 & -8.51 & 0.098 & 1.25 \\
\hline 0.50 & $2 \mathrm{E}-6$ & 0.05 & 8.49 & 0.155 & -8.57 & 0.039 & 0.14 \\
\hline 0.01 & $2 E-8$ & 0.20 & 8.80 & 0.051 & -8.24 & 0.109 & 1.62 \\
\hline 0.01 & $2 \mathrm{E}-8$ & 0.50 & 8.80 & 0.126 & -8.23 & 0.271 & 0.27 \\
\hline 0.001 & $2 \mathrm{E}-10$ & 0.001 & 9.11 & $3 E+6$ & -7.84 & $9 \mathrm{E}+6$ & $1 E-16$ \\
\hline 0.0 & 0.0 & 0.0 & 8.65 & 1688 & -8.56 & 2546 & $4 E-9$ \\
\hline
\end{tabular}

${ }^{a}$ DLM and TLM data over 3 ionic strengths $(0.005,0.030$, and $0.139 M) ; \Delta \mathrm{p} K_{\mathrm{a}} 4 ; C_{1} 0.8 \mathrm{~F} / \mathrm{m}^{2} ; C_{2} 0.2 \mathrm{~F} / \mathrm{m}^{2} ;$ site density 10 sites $/ \mathrm{nm}^{2}$. CCM data at $0.030 M$ ionic strength.

${ }^{b}$ Relative or absolute error estimate for total acid added.

${ }^{c}$ Relative error estimate for hydrogen ion concentration. Absolute error set at zero in all cases.

${ }^{d} \log K^{+}$and $\log K^{-}$for DLM and CCM, or $\log K_{\mathrm{An}}$ and $\log K_{\mathrm{Cat}}$, respectively, for TLM.

e Standard deviation of best-fit value.

${ }^{f}$ No convergence in numeric scheme.

same order as the increase in $N_{\mathrm{s}}$. All models are relatively insensitive to changes in the value of $N_{\mathrm{s}}$ over the range of values that are reasonable for mineral oxides (2-20 sites/ $\mathrm{nm}^{2}$ ). If estimates of $N_{\mathrm{s}}$ can be made within a factor of 10 , then the SCM approach can be used to generate one "best" set of parameters assuming reasonable quality titration data is available.
In the case of the CCM, for an assumed value of $N_{\mathrm{s}}$, the FITEQL best-fit $\log K$ values were relatively insensitive to changes in $C_{1}$, with the $\log K$ values changing less than $0.5 \log$ units over a range in $C_{1}$ of from 0.8 to $1.2 \mathrm{~F} / \mathrm{m}^{2}$.

In the case of the TLM, for an assumed value of $N_{\mathrm{s}}$ and $\Delta \mathrm{p} K_{\mathrm{a}}$, the FITEQL best-fit $\log K$ values were more sensitive to changes 
in the values of $C_{1}$ over the tested range of 0.6 to $2.0 \mathrm{~F} / \mathrm{m}^{2}$, with the $\log K$ values changing as much as $2.0 \mathrm{log}$ units in some cases. The TLM sensitivity analysis showed for $\alpha-\mathrm{Al}_{2} \mathrm{O}_{3}$ and $\alpha-\mathrm{FeOOH}$ that one value of $C_{1}(0.8 \mathrm{~F} /$ $\mathrm{m}^{2}$ ) was better than the others for fitting the data. In all cases, increasing $C_{1}$ resulted in decreasing values for the $\log K$ 's.

The implication of these results is that since a range of $C_{1}$ values may work equally well, the modeler must decide which value should be chosen. Since no method is currently available for measuring interfacial capacitance, the choice is somewhat arbitrary. We recommend, for the purposes of generating a unique set of parameters, using $1.0 \mathrm{~F} / \mathrm{m}^{2}$ for the $\mathrm{CCM}$ and $0.8 \mathrm{~F} / \mathrm{m}^{2}$ for the TLM unless another value gives better FITEQL fits when going through a sensitivity analysis such as the one presented here.

In the case of the TLM, for an assumed value of $N_{\mathrm{s}}$ and $C_{1}$, the value of $\Delta \mathrm{p} K_{\mathrm{a}}$ has a relatively minor effect on the FITEQL, bestfit value of the electrolyte surface reaction constants. For most of the cases studied, a change in $\Delta \mathrm{p} K_{\mathrm{a}}$ from 0 to 3 usually resulted in a change of less than $0.5 \log$ unit. For $\Delta \mathrm{p} K_{\mathrm{a}}$ values greater than 3 , increasing the value had little or no effect on the resulting best-fit value for $\log K_{\mathrm{An}}$ and $\log K_{\mathrm{Cat}}$. Since there currently are no methods for independently measuring the relative importance of the surface acidity versus electrolyte binding constants, no way exists to pick the "best" value for $\Delta \mathrm{p} K_{\mathrm{a}}$ from titration data alone. We propose choosing a $\Delta \mathrm{p} K_{\mathrm{a}}$ of 4 . This approach, combined with the reliable measurement of $N_{\mathrm{s}}$ and choosing a value for $C_{1}$ as described above, allows a "unique" set of parameter values to be estimated for the TLM.

Within reasonable limits, the density and number of data points along the titration curve appear to have little effect on the results and conclusions of this study. Also, the errors in the titration data appear to have little influence on the FITEQL optimized values for surface constants, if they are in the normal range expected for typical titrations. Of course, when a smaller number of data points are used for estimating SCM parameters, there will be a correspondingly larger error bar associated with the best-fit $\log K$ values.

Of all the three models evaluated, the TLM was able to fit the titration data best over the widest range in ionic strength conditions with one set of constants, but it requires the greatest amount of effort to estimate the necessary SCM parameters from titration data. At constant ionic strength, the CCM and TLM were able to model the titration data quite well for all titration data sets. The DLM was not as successful at constant ionic strength conditions, particularly for the $\alpha-\mathrm{Al}_{2} \mathrm{O}_{3}$ and $\alpha$ $\mathrm{FeOOH}$ titration data sets. Even though the DLM was not able to fit the titration as well as the TLM or CCM, the simplicity of the model and the ability to arrive at a unique set of parameter values without the need for arbitrary assignment of parameters makes it an attractive alternative to the other two SCMs.

In the above study we have focused on strategies for obtaining SCM parameters for pure mineral oxide materials. Kent et al. (26) have reviewed the requirements for and the problems associated with characterizing complex mineral systems in terms of SCM parameters. The further development of appropriate experimental protocols for characterizing complex mineral systems will be necessary if SCMs are to be used successfully as sorption algorithms in solute transport models. If the SCM approach described here for proton sorption is to be used to simulate trace metal partitioning, then it must be demonstrated that trace metal partitioning can be successfully modeled using the constants determined in the sensitivity analysis described here. The ability of the SCMs to account for the partitioning of anions and cations at the oxide/aqueous interface over a range of $\mathrm{pH}$ and ionic strength conditions using the constants determined here is the subject of a future paper. 


\section{ACKNOWLEDGMENTS}

This research was supported by Battalle Memorial Institute Pacific Northwestern Laboratories, Contract B-N3975-A-E. The authors especially thank the project managers, Ken Krupka and Jeff Sernie, for their guidance and support of this research effort and their critical review of this manuscript. The critical review by Lynn Katz also greatly improved this manuscript.

\section{REFERENCES}

1. Schindler, P. W., and Stumm, W., in "Aquatic Surface Chemistry" (W. Stumm, Ed.). Wiley, New York, 1987.

2. Hayes, K. F., and Leckie, J. O., J. Colloid Interface Sci. 115, 564 (1987).

3. Hayes, K. F., Papelis, C., and Leckie, J. O., J. Colloid Interface Sci. 125, 717 (1988).

4. Hayes, K. F., Ph.D. thesis, p. 260, Dept. of Civil Engineering, Stanford Univ. Press, Stanford, CA, 1987.

5. Hansen, A. M., Ph.D. thesis, Universidad Nacional Autónoma de México, Mexico City, Mexico, 1989.

6. Yeh, G. T., and Tripathi, V. S., Water Resour. Res. 25, 93 (1989).

7. Westall, J., and Hohl, H., Adv. Colloid Interface Sci. 12, 265 (1980).

8. Koopal, L. K., van Riemsdijk, W. H., and Roffey, M. G., J. Colloid Interface Sci. 118, 117 (1987).

9. Morel, F. M. M., Yeasted, J. G., and Westall, J. C., in "Adsorption of Inorganics at Solid-Liquid Interfaces" (M. A. Anderson and A. J. Rubin, Eds.) Chap. 7. Ann Arbor Sciences, Ann Arbor, MI, 1981.

10. Huang, C.-P., and Stumm, W., J. Colloid Interface Sci. 43, 409 (1973).

11. Healy, T. W., Yates, D. E., White, L. R., and Chan, D., J. Electroanal. Chem. 80, 57 (1977).

12. Dzombak, D. A., and Morel, F. M. M., J. Hydraulic Eng. 112, 588 (1986).

13. Hohi, H., and Stumm, W., J. Colloid Interface Sci. 55, 281 (1976).

14. Sposito, G., "The Surface Chemistry of Soils," Oxford Univ. Press, New York, 1984.

15. Davis, J. A., James, R. O., and Leckie, J. O., J. Colloid Interface Sci. 63, 480 (1978).

16. James, R. O., and Parks, G. A., Surf. Colloid Sci. 12, $119(1982)$.

17. Davis, J. A., and Hayes, K. F., Eds., "Geochemical Process at Mineral Surfaces," ACS Symposium Series, Vol. 323, Amer. Chem. Soc., Washington, DC, 1986.
18. Stumm, W., Ed., “Aquatic Surface Chemistry," Wiley, New York, 1987.

19. Dzombak, D. A., and Morel, M. M., "Surface Complexation Modeling," Wiley, New York, 1990.

20. Hayes, K. F., and Leckie, J. O., J. Colloid Interface Sci. 115, 564 (1987).

21. Hunter, R. J., in "Foundations of Colloid Science," Vol. I, p. 338. Oxford Univ. Press, New York, 1989.

22. Gregg, S. J., and Sing, K. S. W., "Adsorption, Surface Area and Porosity," p. 303, Academic Press, New York, 1982.

23. Yates, D. E., Ph.D. Thesis, University of Melbourne, Australia, 1975.

24. Westall, J. C., Report 82-01, Department of Chemistry, Oregon State University, Corvallis, OR, 1982.

25. James, R. O., Davis, J. A., and Leckie, J. O., J. Colloid Interface Sci. 65, 331 (1978).

26. Kent, D.. B., Tripathi, V. S., Ball, N. B., and Leckie, J. O., Progress Report, Contract \#SNL-25-1891, Sandia National Laboratory, 1986.

27. Smit, W., and Holten, C. L. M., J. Colloid Interface Sci. 78, 1 (1980).

28. Schindler, P. W., in "Adsorption of Inorganics at SolidLiquid Interfaces" (M. A. Anderson and A. J. Rubin, Eds.) Ann Arbor Sciences, Ann Arbor, MI, Chapter 1 (1981).

29. Sprycha, R., J. Colloid Interface Sci. 96, 551 (1983).

30. van Riemsdijk, W. H., Bolt, G. H., Koopal, L. K., and Blaakmeer, J., J. Colloid Interface Sci. 109, 219 (1986).

31. Westall, J., in "Geochemical Processes at Mineral Surfaces" (J. A. Davis and K. F. Hayes, Eds.), ACS Symposium Series, Vol. 323, Chap. 4, Amer. Chem. Soc., Washington, DC, 1986.

32. Smit, W., Holten, C. L. M., Stein, H. N., de Goeij, J. J. M., and Theelen, H. M. J., J. Colloid Interface Sci. 63, 120 (1978).

33. Smit, W., Holten, C. L. M., Stein, H. N., de Goeij, J. J. M. and Theelen, M. M. J., J. Colloid Interface Sci. 67, 397 (1978).

34. Sprycha, R., J. Colloid Interface Sci. 102, 173 (1984).

35. Sprycha, R., and Szczypa, J., J. Colloid Interface Sci. 102, 288 (1984).

36. Pieper, J. H. A., and de Vooys, D. A., J. Electroanal. Chem. 53, 243 (1974).

37. Bousse, L., and Bergveld, P., J. Electroanal. Chem. 152, 25 (1983).

38. Smit, W., J. Colloid Interface Sci. 109, 295 (1986).

39. Smit, W., J. Colloid Interface Sci. 113, 288 (1986).

40. Israelachvili, J. N., in "Intermolecular and Surfaces Forces," Table V, p. 43. Academic Press, New York, 1985.

41. Atkinson, R. J., Posner, A. M., and Quirk, J. P., Inorg. Nucl. Chem. 34, 2201 (1972). 